\title{
Experimental and numerical analysis of a TLP Floating Offshore Wind Turbine
}

Elif Oguz *, David Clelland ${ }^{l}$, Alexander H. Day ${ }^{1}$, Atilla Incecik ${ }^{I}$, Juan Amate López ${ }^{2}$, Gustavo Sánchez ${ }^{2}$, Gonzalo González Almeria ${ }^{2}$

1. Department of Naval Architecture, Ocean and Marine Engineering, Henry Dyer Building, University of Strathclyde, 100 Montrose Street, Glasgow, G4 OLZ, UK

2. Iberdrola Ingeniería y Construcción, Madrid 28050, Spain

${ }^{*}$ Corresponding author; e-mail: e.oguz@strath.ac.uk, phone: +44(0)1415484047

\begin{abstract}
This paper describes an experimental and numerical investigation of the Iberdrola TLP wind turbine concept, TLPWIND, in realistic wind and wave conditions. The TLP was coupled to the NREL 5MW reference turbine and was designed to operate in a water depth of $70 \mathrm{~m}$. The test campaign included free oscillation tests, tests in regular and irregular waves and simulated wind conditions.
\end{abstract}

A Software-in-the-loop approach was adopted to account for the time-varying aerodynamic forces produced by the turbine during the physical experiments. The effect of wind was found to have a significant contribution to the overall response of the platform whilst variation in wave conditions was found to have a relatively small effect on the platform response.

A comparison of results from physical and numerical simulations show that, the numerical predictions from FAST were very close to the results obtained from the experiments in some cases, but in other cases the numerical model failed to accurately predict the platform response.

The results from both studies show the benefits of such TLP structures in terms of motions which are vital to obtain a high power output from a floating offshore wind turbine.

Keywords: offshore wind energy, offshore renewables, tension leg platform 


\section{Introduction}

In order to establish financially viable floating offshore wind turbine designs, the wind energy industry needs to develop cost-effective concepts. In recent years a number of different Floating Offshore Wind Turbine (FOWT) concepts have been proposed in order to meet this goal. Due to time and cost constraints the first design stage of these concepts requires a reliable numerical approach in order to characterise the response of the proposed system.

Each FOWT concept needs to be designed for its specific deployment region which usually means each system requires a unique investigation to assess its behaviour. Building and testing the performance of these systems in full scale in every case is not financially viable.

Tension Leg Platforms (TLP's) have become popular structures in offshore oil extraction and have attracted some interest in the wind energy sector. A challenging topic in this field has arisen from the potential adoption of TLP type wind turbine platforms into water depths of around $70 \mathrm{~m}$ compared to oil and gas TLP structures which normally operate in much greater water depths. The TLP wind turbine platform has recently attracted interest due to the extremely small heave, pitch and roll motions compared to other floating platforms and the potential to offer significantly reduced fabrication costs due to the reduced steel weight compared to fixed offshore wind turbines.

It is critical to be able to predict reliably a FOWT's complex behaviour in the real wind and wave environment which it will experience. The current study aims to examine the reliability of existing numerical and experimental approaches for the prediction of performance of a TLP FOWT. In particular the study addresses the impact of the utilisation of a Software-in-theloop approach for simulating the coupling between the aero- and hydrodynamic excitation, and explores the ability of the widely-used FAST numerical software tool to predict the key response parameters of a TLP FOWT over a range of test cases including free oscillation, regular and irregular waves. Some key aspects of the performance of the particular design studied are highlighted.

The paper presents the results of an extensive experiment campaign on a 1:36.67 scale TLP FOWT employing a $5 \mathrm{MW}$ turbine in a water depth of $70 \mathrm{~m}$ including free oscillation tests, 
regular and irregular wave tests. All of the tests were carried out in a simulated wave and wind environment. Numerical predictions were carried out using a fully coupled aero servo hydro elastic code (FAST) and the predictions are compared with the experimental results.

This paper begins with an overview of the 'state of the art' in floating offshore wind turbine concepts and presents the main challenges of designing a reliable and cost effective floating concept which has low motion response characteristics in order to provide a stable platform for the wind turbine. Following this, a description of the Kelvin Hydrodynamics Laboratory where the experimental investigation was carried out and also the scaling criteria for the model used in the experiments are given in Section 2. An overview of the experimental methodology and procedure for the TLP type wind turbine is presented including the implementation of the Software-in-the-loop (SIL) system. A description of the numerical modelling of the FOWT used in the study is given. The results of free oscillation tests are provided with a comparison of the numerical predictions and experimental measurements of the natural periods for surge and pitch. Following this, the regular wave tests carried out to characterise the behaviour of the structure through the motion and tendon tension RAOs are described and correlation between experimental and numerical calculations is presented. Then, motion responses and tendon loadings of the FOWT under realistic wind and wave conditions are presented with emphasis on the mean responses. Finally, a brief summary of the main results from this work are provided in Section 7.

\subsection{Numerical Studies on Floating Offshore Wind Turbines}

In recent years, the development of numerical simulation tools has increased in order to better predict the performance of FOWT's. Simulation tools have been developed which integrate the aerodynamic models, control system (servo) models, and structural dynamic (elastic) models into a fully coupled simulation environment. Developed for land-based systems these tools have now been extended for use in the offshore environment where the hydrodynamic behaviour must also be included (Jonkman, 2007).

The first full scale spar-buoy type floating wind turbine was deployed off the south-west coast of Karmoy Island, Norway as a part of Hywind demonstration project. In order to simulate the dynamic response of the Hywind spar concept, a computer tool was developed by Skaare et al. (2007). HAWC2, developed by Ris $\varnothing$ National Laboratory is a state-of-the-art aero-elastic code designed to analyse the response of fixed foundation wind turbines. SIMO/RIFLEX was 
developed by MARINTEK to simulate the dynamic response of marine structures. SIMO/RIFLEX and HAWC2 were subsequently integrated and named SIMO/RIFLEX/HAWC2. This code was tested and verified by separate SIMO/RIFLEX and separate HAWC2 simulations. A SIMO/RIFLEX/HAWC2 model of Hywind used in experiments in 2005 was also developed and tested for the same met ocean conditions and included the same blade pitch control system that used in the model scale experiments in MARINTEK laboratory.

According to the IEC 61400-3 design standard for offshore wind turbines, in order to develop a cost-effective, high-performance floating offshore wind turbine an integrated load analysis has to be carried out before a turbine is certified. This analysis is not only a requirement under IEC 61400-3, but it is also important at the concept design stage. The integrated load analysis can be carried out using numerical aero-hydro-servo-elastic simulation tools such as FAST, GH Bladed, or FLEX. These numerical tools are based on an integrated modal and multibody structural-dynamics formulation in the time domain. These codes are preferred by researchers since they are able to carry out numerous design-load scenarios with relatively short computational time. It should be noted that the hydrodynamic loads are usually simulated in these codes using simplified approaches such as Morison's equation which is really only valid for small diameter cylinders. Furthermore, as stated inMatha (2009), "important effects for offshore floating platforms, like free-surface, memory or a typical added-mass-induced couplings between modes of motion in the radiation problem, are ignored" in addition in these codes "the diffraction problem is simplified using G.I.Taylor's long-wavelength approximation".

There are also more advanced simulation codes such as MSC ADAMS and SIMPACK which provide higher-fidelity multibody-dynamics and can integrate more advanced aerodynamics formulations such as CFD, free vortex wake models and structural models. These codes are expensive in terms of computational time and hence they are not currently well-suited to carry out all extensive load case simulations defined in the IEC 61400-3 design standard.

The linear frequency-domain approach which is based on finding the response amplitude operators (RAOs) for the platform's six rigid body modes has been used by a number of researchers. Bulder et al.(2003) carried out a frequency domain analysis for a tri-floater design employing 5MW turbine. The same method was also used by Lee (2005) in order to investigate a 1.5MW turbine, and by Wayman et al.(2006) to analyse a number of TLP and barge concepts. Vijfhuizen (2006) designed a wind and wave power barge which consists of 
5MW turbine with an oscillating water column (OWC). Tracy (2007)carried out a parametric study for a TLP optimisation and slack and taut catenary spar-buoy concepts using a frequency domain approach described by Wayman et al.(2006).

Linear frequency domain approaches, by their nature, do not account for the nonlinear structural dynamics, aerodynamics, hydrodynamics and transient effects. A number of research groups have used time-domain simulation methods to overcome the abovementioned limitations. In order to investigate the effects of platform motions on turbine fatigue loads, a so-called state-domain method was applied by Henderson et al.(2003). Withee and Sclavounos (2004) used a modified version of aero-servo-elastic design code including platform motion and hydrodynamic loading based on Morison's equation.

In this research, all the numerical load analysis was carried out using the GL-certified (Manjock, 2005) aero-hydro-servo-elastic design code FAST: Fatigue, Aerodynamic, Structures and Turbulence developed by the NREL's National Wind Technology Center (NWTC). FAST provides a fully coupled integrated simulation environment for modelling floating offshore wind turbine concepts.

Jonkman (2007) used FAST to analyse the ITI Energy Barge concept, where he defined the dynamic response and extreme loads and instabilities resulting from the dynamic coupling between the turbine and the floating barge system. The effects of the increased pitch motion on the extreme loads and characterisation of the instabilities in yaw are some of the important results from his thesis. Additionally, Jonkman (2010) defined and developed a preliminary FAST model of the well-known OC3 (Offshore Code Comparison Collaboration) Hywind spar-buoy concept as a part of the Benchmark Exercise of Aero-Elastic Offshore Wind Turbine Codes project.

Sclavounos et al. (2007) performed a fully coupled analysis for a floating wind turbine system supporting a 5MW wind turbine moored to the sea bed using pre-tensioned tendons in a TLP arrangement as well as a standard catenary arrangement. The results indicated that TLPs have the potential to offer benefits due to their low RMS accelerations and negligible heave and pitch motions.

A fully coupled dynamic analysis of an FOWT was investigated by Withee and Sclavounos (2004). Fully-coupled time-domain numerical simulations for a 1.5MW wind turbine mounted on a TLP floater were performed to determine the system responses under wind and wave 
forces. The authors indicated that the damping from the turbine rotor appears to obey a linear law and had a similar magnitude to the hydrodynamic damping.

Zhao et al. (2012) developed a new multi-column TLP foundation (WindStar TLP) for the NREL offshore 5MW reference turbine using the same site-specific environmental conditions as the OC3-Hywind (NREL) conditions. FAST was used as a numerical tool to carry out an aero-hydro-servo-elastic coupled analysis for the proposed design. The results indicated that the elasticity of the turbine system and TLP plays an important role in predicting the natural frequencies of the floating wind turbine. Furthermore it was reported that for all conditions the turbine did not excite any of the resonant modes of the platform. All statistics of key parameters were also compared with MIT/NREL TLP design. The results showed that the WindStar TLP exhibited good motion characteristics under extreme wind and wave conditions with a lighter and smaller design.

There are also studies based solely on the optimisation of floating wind turbine foundations. In a study carried out by Bachynski and Moan (2012), five different parametric single-column TLPWTs have been designed and analysed under four different wind-wave conditions by using the Simo, Riflex and Aerodyn numerical tools in a coupled analysis to estimate the platform motions and structural loads on the turbine components and tendons.

Several design codes developed for wind turbines are compared within the framework of Offshore Code Comparison Collaboration Project and its successor (known as OC3 \& OC4) (Jonkman and Musial, 2010). The codes known as FAST, Bladed, ADAMS, HAWC2, 3Dfloat, Simo and SESAM/DeepC were compared for OC3 Phase IV, which addressed the spar-buoy concept called" Hywind". Results for free oscillation tests in surge showed good agreement between codes. FAST was used by both NREL and POSTECH (Pohang University of Science and Technology) and the results generally compare well; however POSTECH's results suggested underestimation of hydrodynamic damping. The results showed that the codes which do not include quasi-static model such as SESAM and DeepC that model the dynamics of the mooring system give higher energy in the spectra of fairlead tension above the peak wave period. Mooring loads were different depending on quasi-static model versus those using a dynamic model. In general, the results show that numerical stabilities can be an issue depending on the version used for simulations. MSC ADAMS and SIMPACK are found to be expensive in terms of simulation time. Therefore, considering issues of accuracy, availability and simulation time, FAST version 7 was selected for the present study and all relevant modules were used to carry out all numerical analysis for this study. 


\subsection{Experimental Studies on Offshore Floating Wind Turbines}

Model scale tests have advantages compared to full scale tests in terms of reduced time, resources and risk. However, there is still a significant need to develop the methodology for experimental testing of FOWT concepts particularly due to the complex nature of the interaction between the hydrodynamics of the underwater structure coupled with the aerodynamic loads imposed by the turbine blades. In this section, experimental studies carried out by researchers to investigate the dynamic behaviour of FOWT concepts are summarised.

An experimental study of the HYWIND 5 MW spar-buoy type FOWT in 1:47 model scale was carried out by Hydro Oil \& Energy at MARINTEK's Ocean Basin Laboratory in Trondheim, Norway in 2005. The first numerical analyses of the motion characteristics of the HYWIND design was presented in Nielsen et al. (2006) with the experimental comparison. Experiments were performed to investigate the design under a wide range of environmental conditions. In addition to this, wind turbine control schemes were also tested.

Roddier et al. (2010) carried out an experimental study using a 1:67 scale model of their semisubmersible WindFloat concept in order to confirm the accuracy of the numerical model developed for the engineering design. The concept has a three-legged foundation and is designed to carry a 5-8MW wind turbine; the first full scale WindFloat was deployed in November 2011. The paper describes the numerical hydrodynamic model of the platform and its mooring system, wave tank testing which included a simplified aerodynamic model of the wind turbine and the development of the coupled model using FAST.

To better understand the behaviour of FOWT's and assess their advantages on the system performance, Goupee et al. (2012) performed experiments on three FOWT concepts in Maritime Research Institute Netherlands (MARIN). Models at 1:50 scale consisting of a TLP, a spar-buoy and a semisubmersible were investigated each carrying the NREL 5MW reference turbine. Tests included free oscillation tests and tests in irregular sea states. In order to achieve high-quality dynamic wind environments, a novel wind generator was designed in order to generate low swirl and turbulence intensity in the flow field. The paper summarised the relative performance advantages of the three concepts in terms of global motions, tower dynamics and the mooring system response. They concluded that for a TLP type wind turbine, although the wind loading increases the pitch response of the system, the pitch response is still very small. It was observed that the operating wind turbine damped the second order pitch response of the spar buoy and the semisubmersible. The results in their paper are constrained within the specific load and design cases so the results cannot be generalised. 
Martin et al. (2012) published a paper describing the experimental methodology used to compare three FOWT concepts; TLP, spar buoy and semi-submersible. In order to increase the aerodynamic performance of the rotor roughen the leading edge of the model blade was artificially roughened in order to trip the boundary layer transition. It was reported that this method may cause erratic wind turbine behaviour and as such should only be used for fine tuning rather that a complete solution for modelling wind turbine aerodynamic performance. It was suggested that the best approach is to redesign the rotor and use the other techniques sparingly to fine tune the model thrust forces.

Nihei and Fujioka (2010) presented tank test results for a 1:100 scale TLP type FOWT incorporating three rotating blades. Tests were carried out in both waves and wind. Similar to Goupee et al. (2012) their results showed that the blade-wind interaction has a beneficial effect of reducing the floater pitch motion and in addition also decreases the mooring line vibrations.

In order to investigate the hydrodynamic performance of a TLP FOWT a test campaign was carried out by CEHINAV-UPM research group for Iberdrola and published by Rodriguez et al. (2014) . This concept consisted of a central cylindrical column with four square section horizontal pontoons at its base and each pontoon connected with two tendons to the sea bed. Regular, operational, survival, failure and transport tests performed were for a simulated $80 \mathrm{~m}$ water depth. The paper presents the experimental setup, free decay tests, regular wave motion RAOs, irregular wave responses, tendon loads and accelerations. In order to include wind effect into the tests a calibrated turbine was used and controlled with the data measured through real time platform motion tracking. They also compared their results with available in-house numerical simulations and other results found in literature. Their experimental results indicated that the natural periods and damping values are similar to those published in the literature. The surge values were slightly smaller than reference values which was put down to the reduced water depth. All the RAOs were very small except surge which is typical for TLPs. Due to the coupling of surge and heave motions, the heave motion response contained components at twice the fundamental wave frequency. It is also reported that no slack in the tendons occurred during the testing period.

Nihei et al. (2014) presented collaborative work on FOWT's carried out by four universities. They aimed to investigate the performance of different FOWT platforms which can support a 5 MW turbine. Osaka Prefecture University adopted a TLP concept, Yokohama National University used semi-submersible concept, Nihon University used a spar concept and Osaka 
University adopted a semi-submersible with a single-point mooring. All tests were conducted using the same met ocean conditions and the main focus was on the motion performance in terms of RAOs. All the concepts showed good motion performance. The TLP exhibited the best performance in term of motion reduction whereas the spar had the largest accelerations in almost all environmental conditions. Observations showed that gyration effects influenced the spar concept more than the others. The results indicated that there was no impact on RAOs due to the wind except for the single-point moored semi-submersible which exhibited larger coupling effects between the main floater and the mooring system under the wave and wind conditions.

With growing interest in floating offshore wind concepts, tank tests will continue to play an important role in investigating the performance of FOWT's as well as providing valuable data to verify the results of numerical calculations.

\section{Experiment Methodology}

Tank testing in a simulated wind and wave environment is a key part of the design process for the development of floating offshore wind turbines (Oguz et al. 2016). Although an extensive model test campaign can be costly and time-consuming such model scale tests can provide accurate results providing great care is taken. The application of such techniques to determine the performance of FOWTs allow designers to assess performance at the early design stage enabling any necessary corrective action to be taken before the FOWT is deployed.

\subsection{Experimental Setup}

The model tests were carried out in the Kelvin Hydrodynamics Laboratory at the University of Strathclyde. The tank has dimensions of $76 \mathrm{~m}$ length $\mathrm{x} 4.6 \mathrm{~m}$ width $\mathrm{x} 2.5 \mathrm{~m}$ depth.

The model was installed in the centre of the tank both longitudinally and transversely on a mounting frame installed on the tank base to allow the model to be rotated through 45 degrees (Figure 2). The plan and profile view of the tank showing the experimental setup is given in Figure 1. 


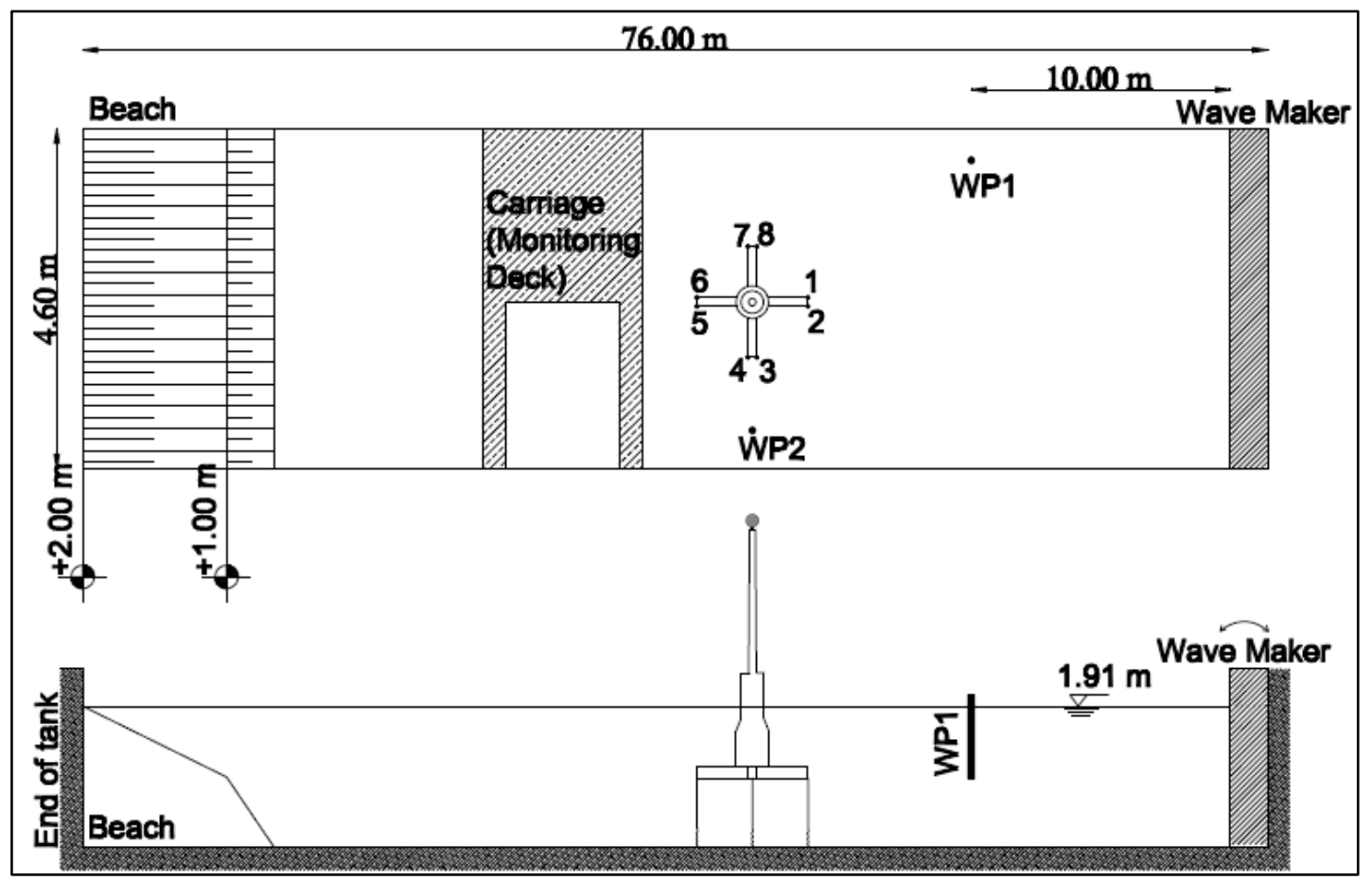

Figure 1 Schematic view of the model in the tank

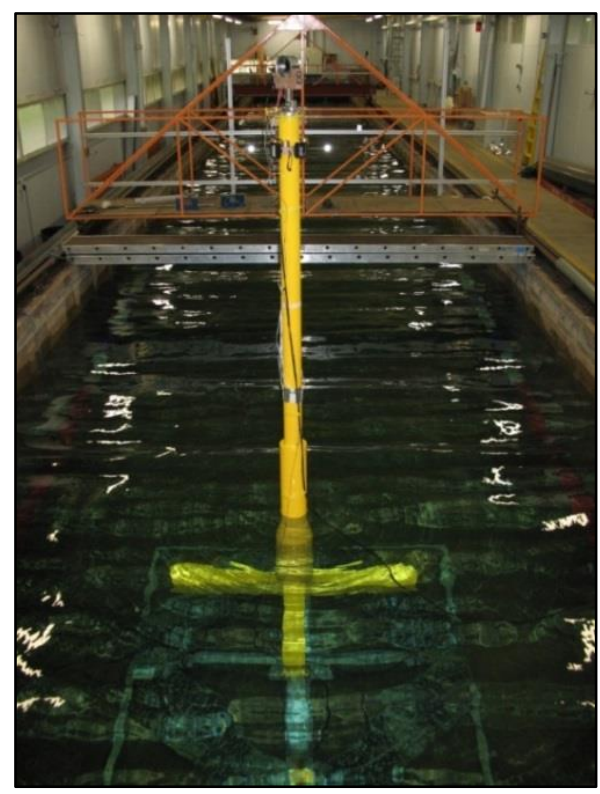

Figure 2 View of the model in KHL tank looking towards wave maker

\subsection{Instrumentation}

The instrumentation package installed on the model summarised in Table 1. The water surface profile was measured using 2 wave probes; one located $10 \mathrm{~m}$ from the face of the wave maker (tank wave) and one in-line with the model (model wave). The six-degree-of-freedom floating body motions were measured using a Qualisys optical tracking camera system. Turbine thrust was measured using a load cell located at the base of the fan. Tendon tensions were measured at the bottom of the tank using 8 underwater load cells. Strain gauges were installed to 
measure tower bending moments. A 3 axis accelerometer was mounted at the model VCG and a second 3 axis accelerometer mounted at the top of the tower to obtain the accelerations at $\mathrm{COG}$ and at tower. Bending moments and accelerations are not presented in this paper.

Table 1 Instrumentation summary

\begin{tabular}{|c|l|l|}
\hline ID & Contents & \multicolumn{1}{c|}{ Measurement } \\
\hline $\mathbf{1}$ & Electric Ducted Fan (EDF) & \\
\hline $\mathbf{2}$ & Beam Load Cell & Fan thrust \\
\hline $\mathbf{3}$ & Wireless accelerometer & Acceleration at nacelle \\
\hline $\mathbf{4}$ & Qualisys motion capture & 6 DOF motion of platform \\
\hline $\mathbf{5}$ & Strain gauges & Tower bending moments \\
\hline $\mathbf{6}$ & Wired accelerometer at VCG (inside) & Acceleration at CG \\
\hline $\mathbf{7}$ & Water proof camera & \\
\hline $\mathbf{8}$ & Tendon wires (8 in total) & \\
\hline $\mathbf{9}$ & Springs (8 in total) & \\
\hline $\mathbf{1 0}$ & Under water load cell (8 in total) & Tendon tension \\
\hline & & \\
\hline
\end{tabular}

Since tendon performance is critical to the performance of a TLP, great care was taken to ensure that pretention and stiffness were correctly adjusted. The eight tendons were constructed using stainless steel wires, and the full-scale tendon stiffness was modelled using calibrated springs. The tendons were attached at both ends to universal joints to minimize friction. Since the weight of the tendons could not be correctly scaled, appropriate corrections were made to the expected value of the pre-tension to allow the model to be installed correctly. After a process of careful adjustment, the error in the mean tendon tension was less than $3 \%$ of the target value.

Due to the complex nature of the instrumentation package deployed a set of tests were carried out daily in order to ensure that the instruments were performing appropriately.

\subsection{Model description}

The principle dimensions of the tank as well as the capability of the wave maker are the most important issues which determine the scale factor to be used for the experiments. Since Reynolds number scaling is not being used the model size should be as large as possible in order to mitigate scaling issues related to viscous effects. Secondary factors such as ease of model construction, availability of materials and instrumentation systems also influence the scale factor.

In order to have the target values of maximum significant wave height and achieve the target water depth, (measured to the bottom of the tendons) of $1.90 \mathrm{~m}$ the scale was selected to be 
1:36.5. A final scale of $1: 36.67(\lambda=36.67)$ was selected, allowing the tower to be constructed from readily available stock aluminium tubes.

This is relatively large scale compared to those tested using working turbines, for example in the OC3 and OC4 projects, which were tested at 1:50. Dimensions for the full scale TLP and its scale model along with other parameters are given in Table 2.

Table 2 TLP wind turbine prototype and 1:36.67 model dimensions

\begin{tabular}{|l|c|c|c|}
\hline Item & Full scale & Units & Model Target \\
\hline Span & 55.00 & $\mathrm{~m}$ & 1.500 \\
\hline Pontoon width & 4.40 & $\mathrm{~m}$ & 0.120 \\
\hline Pontoon height & 5.50 & $\mathrm{~m}$ & 0.150 \\
\hline Central column diameter & 8.20 & $\mathrm{~m}$ & 0.224 \\
\hline Central column height & 23.17 & $\mathrm{~m}$ & 0.632 \\
\hline Transition piece height & 6.33 & $\mathrm{~m}$ & 0.173 \\
\hline Tower toe diameter & 5.59 & $\mathrm{~m}$ & 0.152 \\
\hline Tower upper diameter & 3.87 & $\mathrm{~m}$ & 0.106 \\
\hline Tower height & 71.10 & $\mathrm{~m}$ & 1.938 \\
\hline Water depth (MSL) & 70.00 & $\mathrm{~m}$ & 1.910 \\
\hline Draft (MSL) & 35.50 & $\mathrm{~m}$ & 0.970 \\
\hline Freeboard & 16.50 & $\mathrm{~m}$ & 0.450 \\
\hline Tendon length & 34.50 & $\mathrm{~m}$ & 0.940 \\
\hline Tendon diameter & 90.00 & $\mathrm{~mm}$ & 2.450 \\
\hline
\end{tabular}
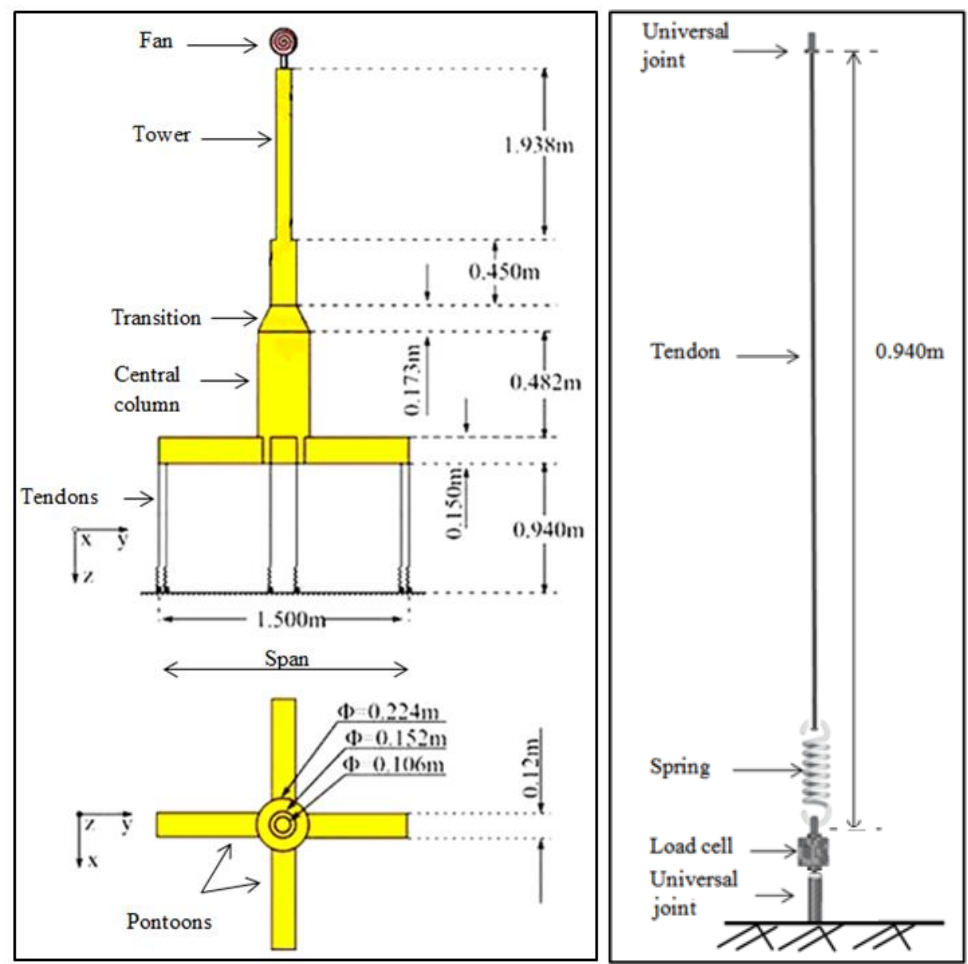

Figure 3 TLP wind turbine dimensions in model scale and description 
The tendon numbering is shown in Figure 4.

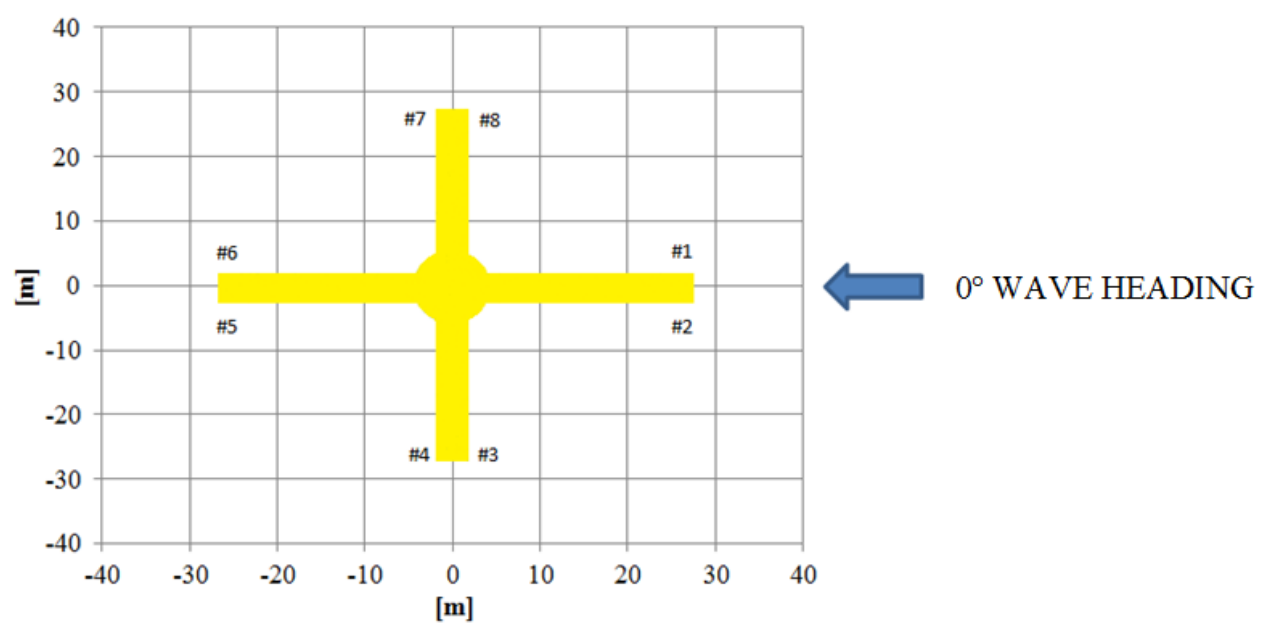

Figure 4 Tendon numbering

Properties of the NREL 5MW turbine are given in Table 3.

Table 3 Gross Properties Chosen for the NREL 5-MW Baseline Wind Turbine (Jonkman et al., 2009)

\begin{tabular}{|l|l|}
\hline Rating & 5 MW \\
\hline Rotor Orientation, Configuration & Upwind, 3 Blades \\
\hline Control & Variable Speed, Collective Pitch \\
\hline Drivetrain & High Speed, Multiple-Stage Gearbox \\
\hline Rotor, Hub Diameter & $126 \mathrm{~m}, 3 \mathrm{~m}$ \\
\hline Hub Height & $90 \mathrm{~m}$ \\
\hline Cut-In, Rated, Cut-Out Wind Speed & $3 \mathrm{~m} / \mathrm{s}, 11.4 \mathrm{~m} / \mathrm{s}, 25 \mathrm{~m} / \mathrm{s}$ \\
\hline Cut-In, Rated Rotor Speed & $6.9 \mathrm{rpm}, 12.1 \mathrm{rpm}$ \\
\hline Rated Tip Speed & $80 \mathrm{~m} / \mathrm{s}$ \\
\hline Overhang, Shaft Tilt, Precone & $5 \mathrm{~m}, 5^{\circ}, 2.5^{\circ}$ \\
\hline Rotor Mass & $110,0000 \mathrm{~kg}$ \\
\hline Nacelle Mass & $240,000 \mathrm{~kg}$ \\
\hline Tower Mass & $347,460 \mathrm{~kg}$ \\
\hline Coordinate Location of Overall CM & $(-0.2 \mathrm{~m}, 0.0 \mathrm{~m}, 64.0 \mathrm{~m})$ \\
\hline
\end{tabular}

\subsection{Software-in-the-loop approach}

For floating offshore wind turbines (FOWTs) there is generally significant coupling between the forces generated by the rotor and the response of the system as a whole. This coupling will affect many aspects of the platform dynamics; in particular the turbine aerodynamics will contribute to the motion damping of the system in modes which affect instantaneous inflow to the turbine. This can affect key parameters such as the accelerations at the nacelle. The mean aerodynamic thrust loads will generate a mean mooring offset which will affect the peak and long-term mooring loads and may in some cases have a significant impact on some modes of motion while the mean torque on the rotor will generate heeling moments on the floater. In 
addition to the aerodynamic loads, the turbine generates gyroscopic moments on the floater, which may excite undesirable motions - for example a turbine pitching in co-linear wind and waves will generate yawing moments. There may also be some coupling between the blade pitch control system and the platform motions which may result in instabilities of the system.

One possible method of modelling a floating wind turbine in the laboratory environment is to employ a working rotor in a wind field generated by a series of fans. Due to the large blade diameter and light weight of modern wind turbines, the construction of the scaled rotor in order to achieve correct weight and structural properties, can be very challenging.

A simple approach to simulating the thrust load from the wind is to use a fan running at a constant speed to generate a pre-defined value of thrust (PT).

A more sophisticated approach uses a "software-in-the-loop" (SIL) approach in which an active control system drives a fan in real time to simulate the instantaneous aerodynamic thrust load on the turbine in a turbulent wind field.

The key benefits of SIL approach are summarised below:

- The tests can take place without the need for deployment of a wind generation system in the test tank.

- There is no need to construct a scale-model of the rotor and drive

- The scale of the tests is dictated only by the hydrodynamics of the floater, which in this case allows a test at relatively large scale (e.g. the model scale was twice that used in Shin et al. (2013))

- The tests procedure can replicate the forces generated by turbulent or steady wind in a variety of directions relative to the wave heading

- The impact of the turbine control system and blade elasticity on the thrust load may be modelled in the tests

- Correct simulation of the aerodynamic drag load on the tower and parked turbine in extreme conditions is possible

- Some special cases, such as emergency stop tests can be simulated with correct fullscale behaviour

The SIL system deployed in these tests only attempts to simulate the aerodynamic thrust forces. Gyroscopic moments and aerodynamic torque were neglected. For a TLP the pitch motions are small, and hence the pitch-yaw coupling related to the gyroscopic effects of a 
pitching rotor are likely to be small. Similarly the roll stiffness is high and hence the impact of rotor torque will be small. Hence it is felt reasonable to neglect these effects in this case.

The SIL control system deployed in the present test campaign was developed by CENER (Centro Nacional De Energias Renovables). A number of steps are required to implement the system.

1. Waves generated by wave maker excite the 6 DOF motions of the model which are measured in real time using a Qualisys motion tracking system and sent to the SIL control computer.

2. The SIL computer runs a modified version of the FAST aero-hydro-servo-elastic code in which the standard hydrodynamic calculations to find instantaneous values for platform position, attitude and velocities are replaced, in real time, by the values obtained from the tank measurements.

3. Control actions determine the nature of the wind field e.g. turbulent or constant.

4. FAST calculates the aerodynamic thrust expected due to the instantaneous platform kinematics and dynamics of the wind field.

5. The instantaneous thrust demand is sent to the fan controller causing the fan to rotate at the speed associated with the target value of thrust.

Figure 5 shows an overview of the SIL process. 


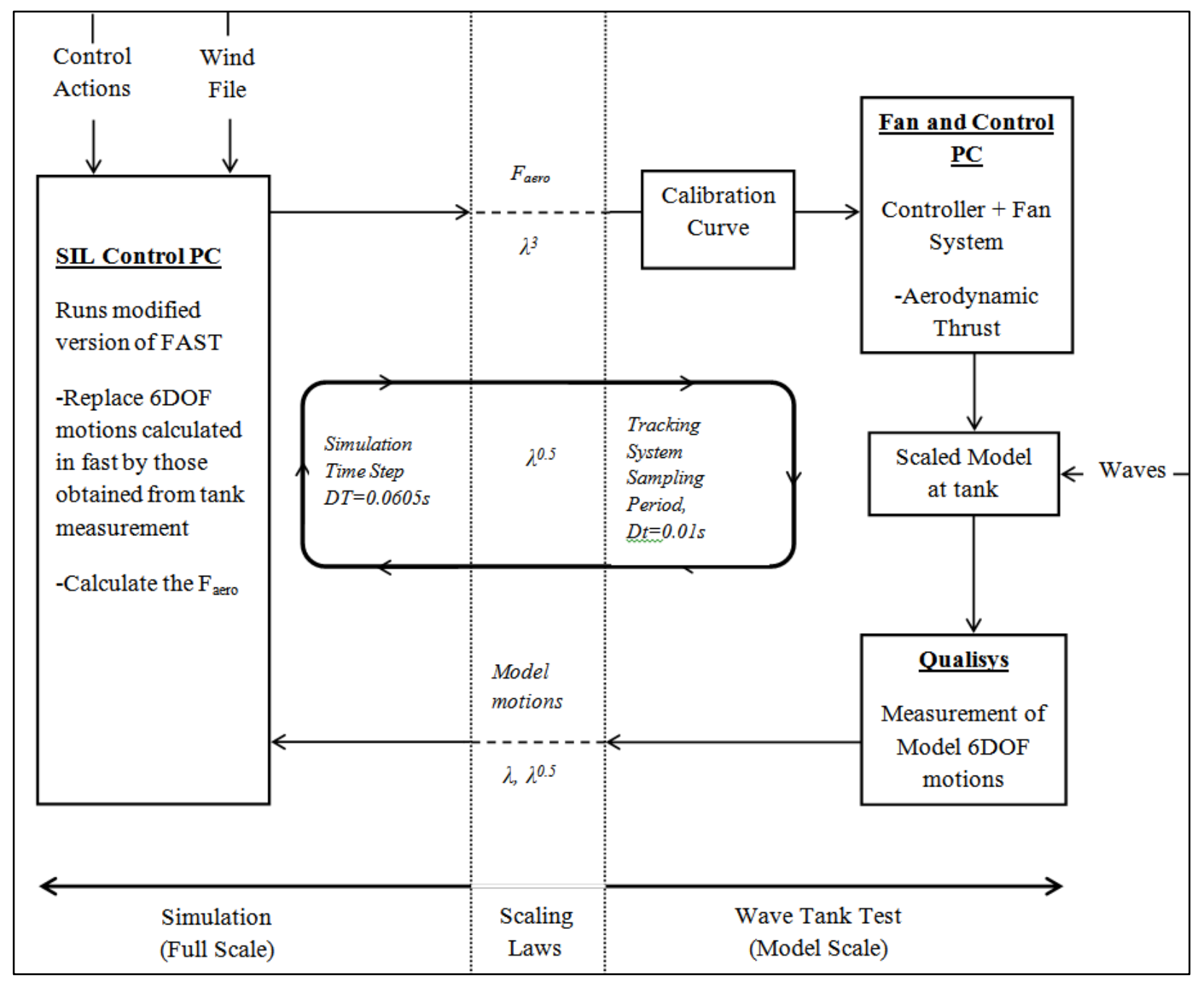

Figure 5 Software-in-the-loop (SIL) Method Diagram (adopted from Müller et al. 2014)

\subsection{Overview of Test Matrix}

The tests consisted of free oscillation tests in calm water, regular wave tests and irregular wave tests in different environmental conditions. Tests were also carried out with combinations of no wind, steady wind and turbulent wind. A summary of the test matrix is given in Table 4.

Table 4 Summary of System Identification Tests

\begin{tabular}{|c|c|c|}
\hline Test Type & Measurements & $\begin{array}{l}\text { Descriptions (in Full } \\
\text { Scale) }\end{array}$ \\
\hline Free Oscillation Tests & $\begin{array}{l}\text { System natural periods and total } \\
\text { damping }\end{array}$ & Surge, pitch \\
\hline Free Oscillation + Wind & Damping contribution from wind & Surge \\
\hline Regular Wave Tests & Linear Response Characteristics (RAOs) & $\begin{array}{l}\text { Period Range : } 6 \mathrm{~s}-30 \mathrm{~s} \\
\text { Wave Height }: 2 \mathrm{~m} \\
\left(0^{\circ} \text { Heading }\right)\end{array}$ \\
\hline $\begin{array}{l}\text { Regular Wave Tests + } \\
\text { Wind }\end{array}$ & $\begin{array}{l}\text { Linear Response Characteristics include } \\
\text { wind }\end{array}$ & $\begin{array}{l}\text { Period Range : } 6 \mathrm{~s}-30 \mathrm{~s} \\
\text { Wave Height }: 2 \mathrm{~m} \\
\left(0^{\circ} \text { Wave heading }\right)\end{array}$ \\
\hline
\end{tabular}




\begin{tabular}{|l|l|l|}
\hline $\begin{array}{l}\text { Irregular Wave Tests }+ \\
\text { Wind }\end{array}$ & System behaviour under sea states & $\begin{array}{l}8 \text { Sea states }\left(0^{\circ} \text { Wave }\right. \\
\text { heading }) \\
\left(0^{\circ} \text { and } 225^{\circ} \text { wind }\right. \\
\text { direction }) \\
\text { Running time }: 3 \text { hours }\end{array}$ \\
\hline
\end{tabular}

\section{Numerical modelling of TLPWIND}

This section presents a description of the numerical tools and the model of the TLPWIND concept.

\subsection{Simulation Tools used for Model Development}

Fatigue, Aerodynamics, Structures and Turbulence (FAST) is an open-source code developed by researchers from the National Renewable Energy Laboratory (NREL) (Jonkman, 2007). FAST consists of a number of modules which deal with wind fields, blade aerodynamics, platform hydrodynamics, structural dynamic, moorings and turbine controllers. Figure 6 gives an overview of the structure of FAST including the various modules which make up the main programme.

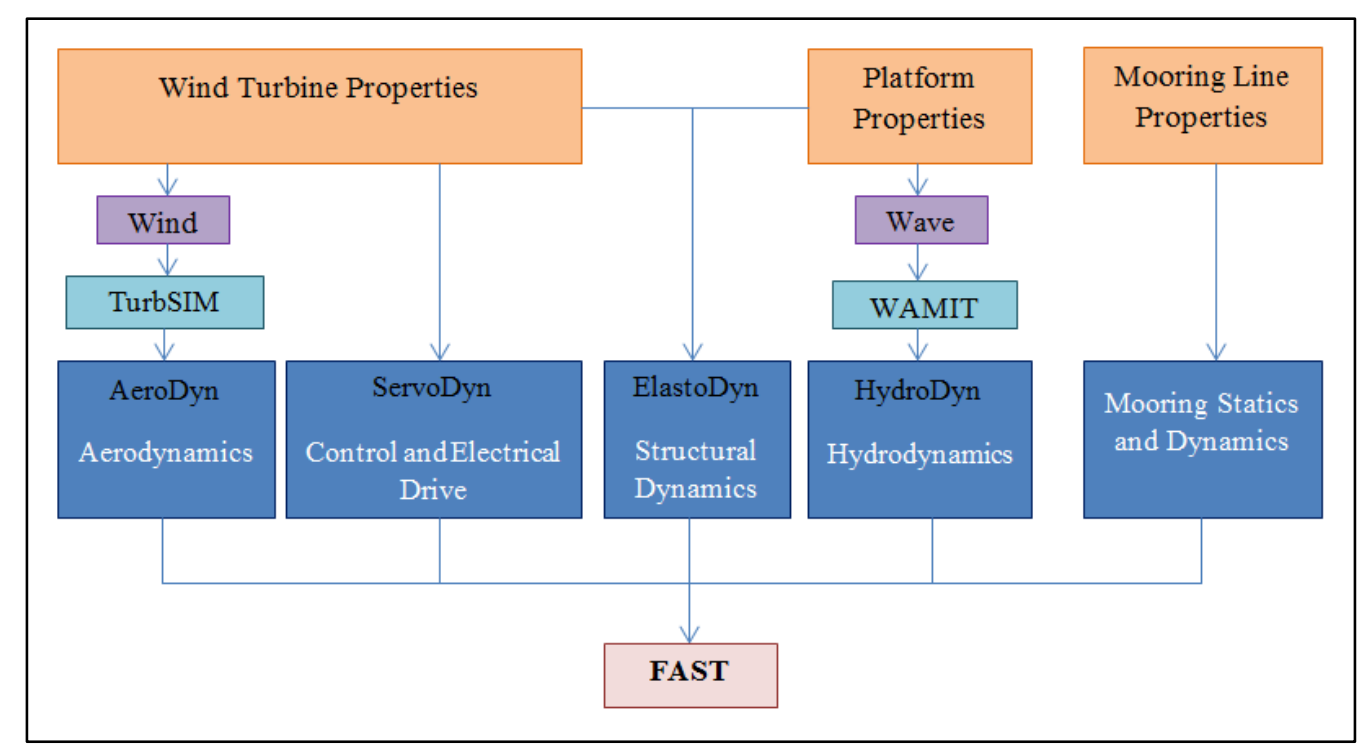

Figure 6 FAST Structure

\subsection{TLPWIND numerical model}

Hydrodynamic coefficients were calculated in WAMIT and are then input to the HydroDyn module in FAST. A parametric study was carried out to compare numerical convergence against computational time. The study showed that a $72 \times 50$ element mesh shown in Figure 7 provided a good balance. The model was used for all of the numerical simulations. 


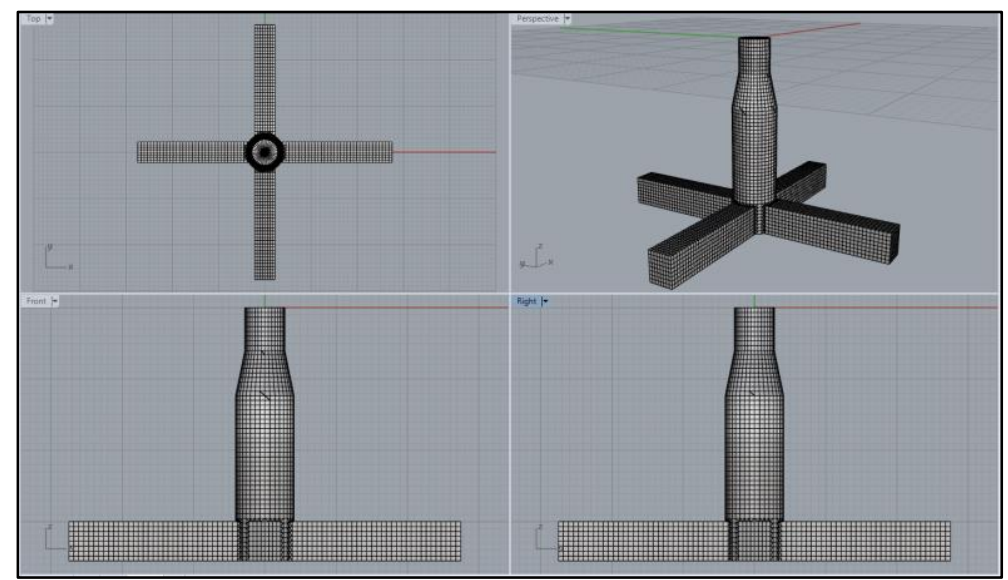

Figure 7 Geometric file of proposed FOWT

\section{Free Oscillation Tests}

Four sets of free oscillation tests were carried out to characterise the natural periods of the model (numerical and physical) in surge and pitch. Each set of test were repeated at least ten times in order to reduce errors due to experimental bias. The surge tests were carried out for three wind conditions: no wind, constant predefined thrust (PT), and software in the loop (SIL) controlled thrust. The PT and SIL tests were performed at the rated turbine wind speed of $11.4 \mathrm{~m} / \mathrm{s}$. Pitch tests were carried out for the no wind condition. The experiments were carried out by displacing the structure in the surge/pitch direction and carefully releasing it. The numerical test were performed by setting wind and waves to zero and introducing a small initial offset in the FAST platform file. Experiment and numerical results for the surge (no wind) case are shown in Figure 8.

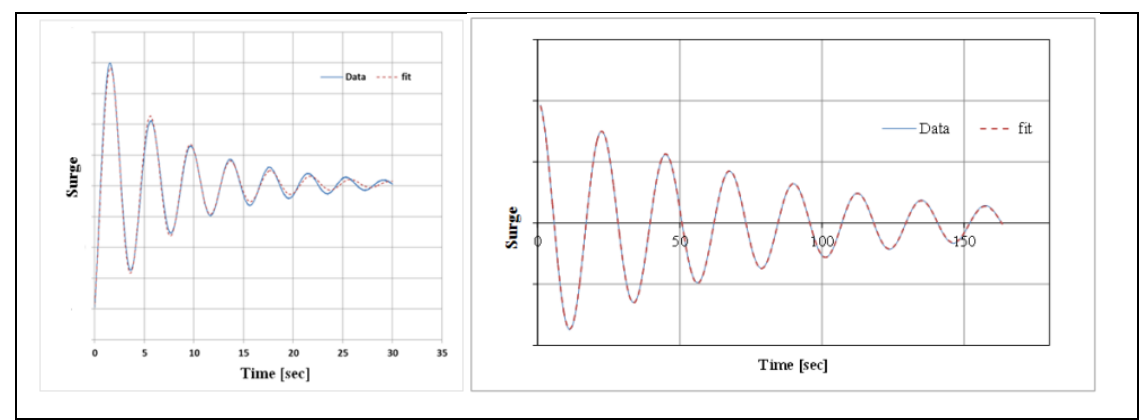

Figure 8 Example of free oscillation tests (no wind case)

The natural periods obtained from the numerical model and the scaled results from the experiments are given in Table 5. The repeatability of the natural period is good for surge in no wind (standard deviation 0.1) and with predefined thrust (standard deviation 0.2). 
Table 5 Surge and pitch natural periods for FOWT

\begin{tabular}{|l|l|l|l|}
\hline Test condition & Experiment [sec] & Numerical [sec] & Error [\%] \\
\hline Surge no wind & 24.376 & 22.475 & 7.70 \\
\hline Surge PT 11.4m/s & 24.344 & 22.468 & 7.70 \\
\hline Surge SIL 11.4m/s & 24.649 & 22.355 & 9.31 \\
\hline Pitch no wind & 2.56 & 2.522 & 1.5 \\
\hline
\end{tabular}

Surge natural periods obtained from the numerical model show reasonable correlation with experiment measurements. The natural periods in surge obtained from experiments are slightly longer than those of the numerical simulation in all three cases. In the cases with no wind and with predefined thrust it is presumed that this is largely due to the neglect of viscous damping in the potential flow based numerical modelling. In particular it may be expected that any flow separation around the bluff bodies of the pontoons will not be represented using a potential flow approach. Since the effect of flow separation is likely to be less important in pitch, this might explain why the comparison of the pitch results showed much better correlation between the numerical prediction and experiment measurements although there was a larger scatter in the pitch experiment results compared to those for surge. However it should also be noted that the discrepancy in period is larger for the SIL case than for the other two cases, suggesting that some additional effects are present, which may be related to the unsteady aerodynamics and turbine control.

\section{Motion RAOs and tendon transfer functions}

In this section the motion RAO's and tendon tension transfer functions obtained from the experiments are compared to those from the numerical results for $0^{\circ}$ head seas with no wind case. 


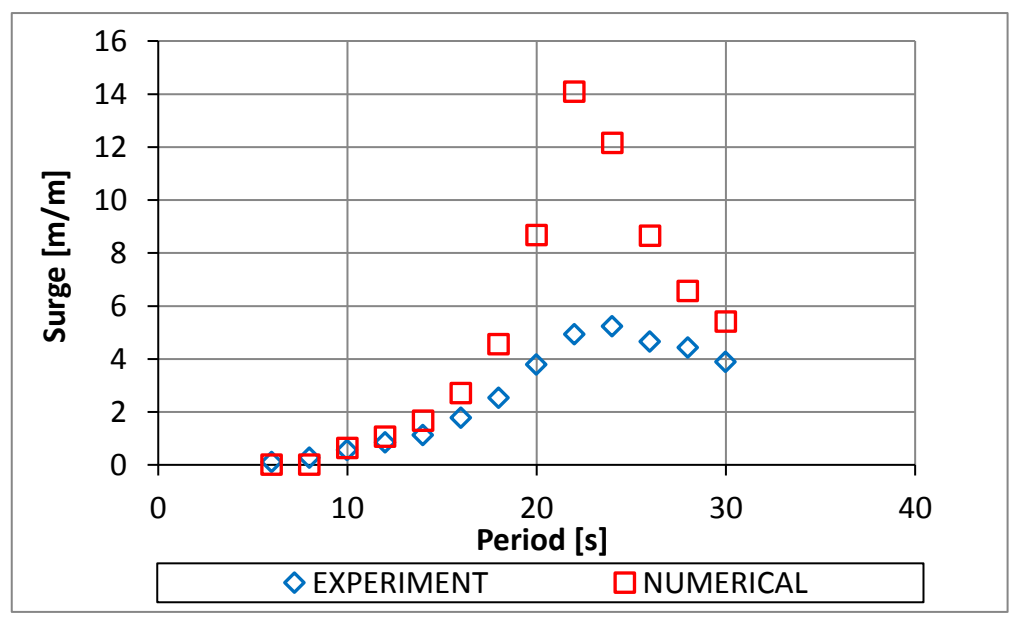

Figure 9 Comparison of surge motion

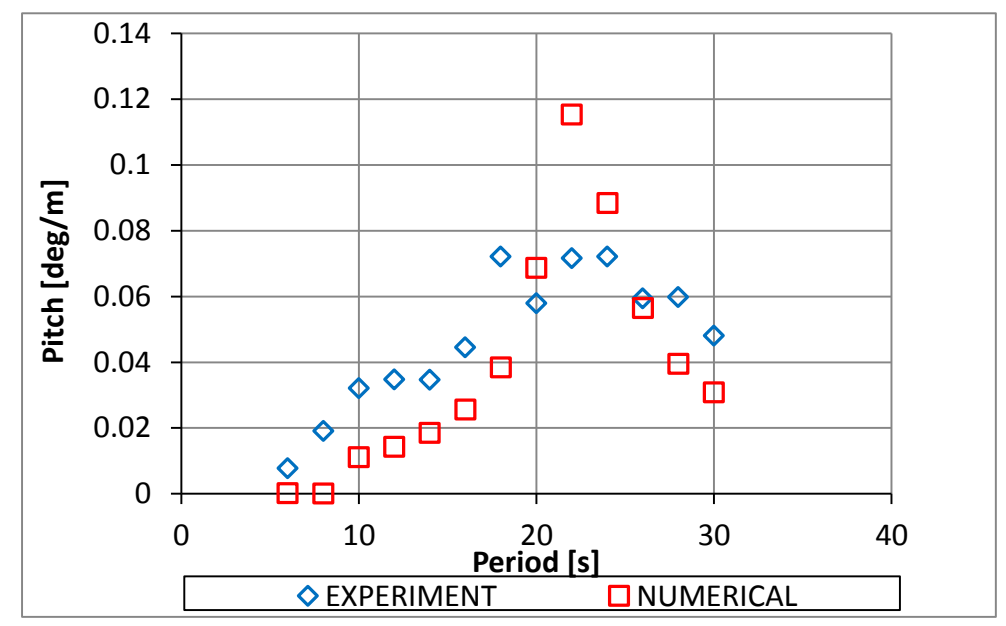

Figure 10 Comparison of pitch motion

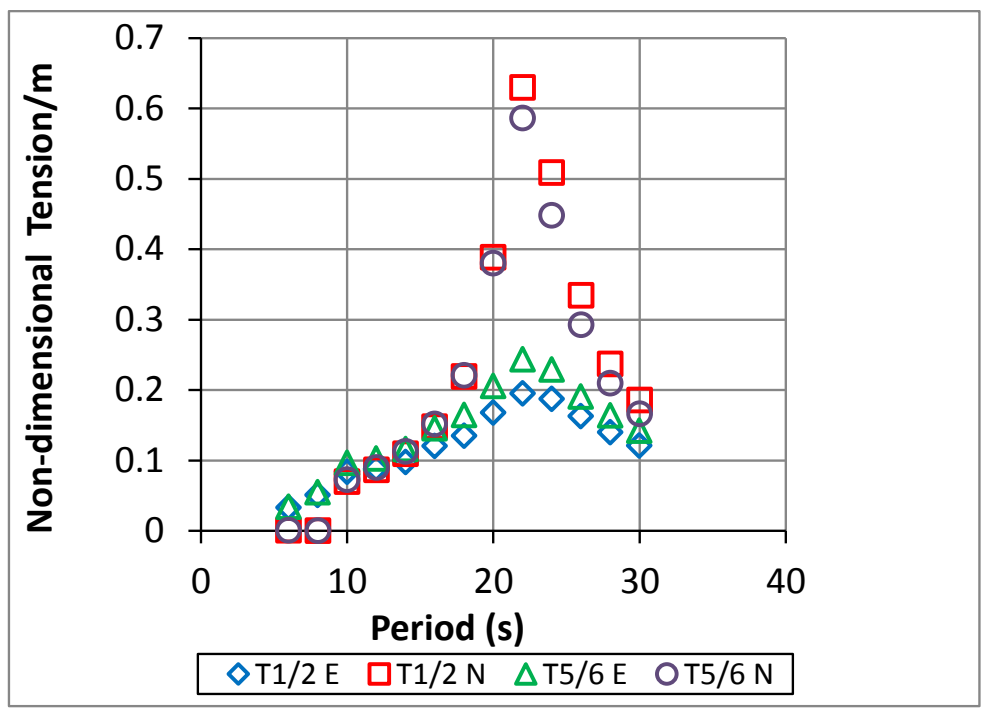

Figure 11 Average front-back tendon transfer functions 


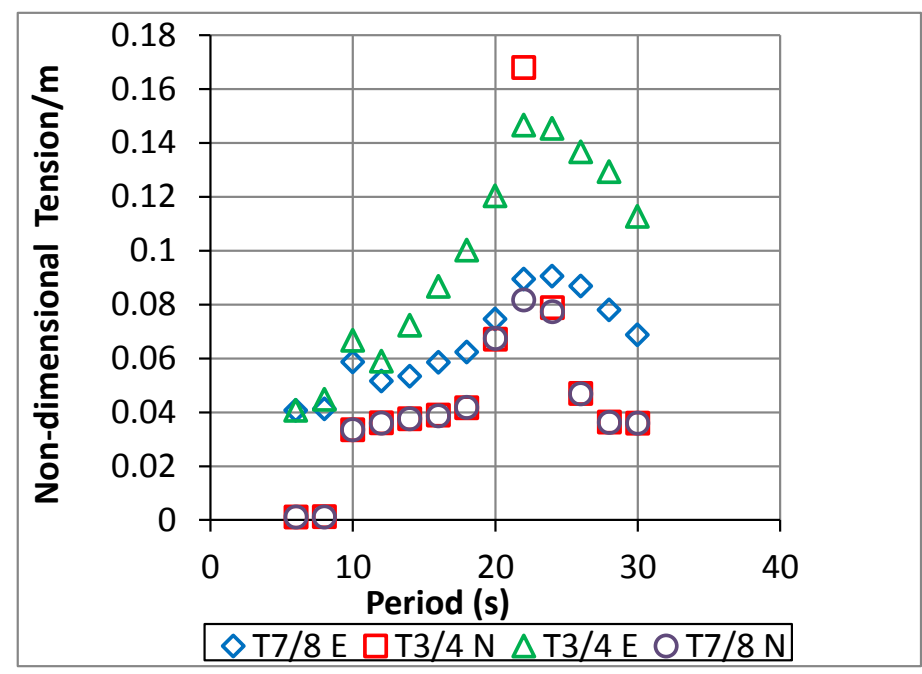

Figure 12 Average side tendon tension transfer functions

All of the motion and tension forces responses show good agreement for wave periods between 5 to 15 seconds and above around 28 seconds. The pitch motions give the closest agreement between the measurements and numerical predictions over the whole range of wave periods. For the remaining responses the numerical predictions substantially overestimate the experimental values particularly in the region of the surge natural period (2225 seconds) where damping dominates. As reported in Wayman et al. (2006)the RAO in surge of the MIT/NREL TLP (benchmark study) shows a large spike at around its natural frequency similar to the results presented here. In order to investigate the viscous damping effect on this spike, Wayman et al. (2006) added 2 different viscous damping ratios. The results showed that as viscous damping increases, the peak responses decreases. This explains the overestimated RAO values around the surge and pitch natural periods. The free oscillation test data were analysed to give linear and quadratic damping for the platform. In principle this data might have been used to improve the correlation between numerical results and experimental predictions. However the version of FAST used for this study did not allow additional viscous hydrodynamic damping to be deployed in the solution of the platform motions, and it is presumed that this lack of viscous effects leads to the overestimation of the surge response at the peak of the RAO. It is interesting to note that the agreement between experiments and numerical prediction for the front-back tendon tensions is much better than the agreement for the surge motions, giving more confidence in the numerical prediction for the peak tendon tensions. 
The largest dynamic tension forces were observed for the down wave tendons (5 and 6) with the side tendons showing the smallest variation. Maximum tension forces coincided with the maximum surge motion at a period of around 24 seconds. The effect of the wind model did not significantly affect the dynamic tension forces.

A subset of the motion RAO's and tension forces transfer functions obtained from the experimental results are compared to those from the numerical results for $0^{\circ}$ head seas with no wind cases. In general good correlation was evident over the 5-20 seconds wave period range whilst the responses were over predicted in the region of the surge natural period.

\section{Irregular Wave Tests}

This section describes the experimental and numerical study carried out in simulated realistic environmental conditions. The FOWT was subjected to eight sea states and seven wind speeds with two different wind directions. The response of the structure to these inputs was obtained from the experiments and for each case was also computed numerically.

The aim of this study was to characterise the motion responses and the tendon loadings of the FOWT under realistic conditions and to compare the experimental results with the numerical predictions.

\subsection{Environmental and Test conditions}

In order to characterise the behaviour of the FOWT during its entire deployment period, the appropriate wind and wave conditions in the deployment area (North Sea) were selected based on an analysis of the proposed site JONSWAP spectra for a range of $\mathrm{H}_{\mathrm{s}}$ and $\mathrm{T}_{\mathrm{p}}$ values were selected for the experiment and numerical study. Turbulent wind fields based on the IEC Kaimal power spectral density function (1) for a range of turbulence intensities were selected.

$$
S_{k}(f)=\frac{4 \sigma_{K}^{2} L_{K} / \bar{u}_{h u b}}{\left(1+6 f L_{K} / \bar{u}_{h u b}\right)^{5 / 3}}
$$

The same turbulent wind data was used in the experiments, via the SIL system, and the FAST numerical study. Constant wind data using values corresponding to the mean value of the turbulent cases were also considered in the numerical simulations in order to provide a comparison between steady and turbulent wind conditions.

Table 6 shows the environmental conditions selected for the FOWT study. The table shows the relationship between sea state and the mean wind speed at the hub height of the NREL 
5MW turbine. The turbine has a cut-in speed of $3 \mathrm{~m} / \mathrm{s}$, a rated speed of $11.4 \mathrm{~m} / \mathrm{s}$ and cut-out speed $25 \mathrm{~m} / \mathrm{s}$ (see Table 3 ). One severe condition representing a $38.76 \mathrm{~m} / \mathrm{s}$ wind speed (turbine shut down) was also tested corresponding to 100 year event in the North Sea. Turbulence intensity ranged from $13.37 \%$ to $29.69 \%$ percent. The constant wind cases used the mean wind speed values in Table 6.

Table 6 Environmental conditions for numerical and experiment study

\begin{tabular}{|c|c|c|c|c|c|}
\hline Sea State & $\mathbf{H}_{\mathbf{s}}[\mathbf{m}]$ & $\mathbf{T}_{\mathbf{p}}[\mathbf{s}]$ & Gamma & Mean Wind Speed [m/s] & Turbulence intensity [\%] \\
\hline $\mathbf{N 1}$ & 4.55 & 9.00 & 2.45 & 11.40 & 20.45 \\
\hline $\mathbf{N 2}$ & 1.50 & 6.61 & 1.00 & 11.40 & 20.45 \\
\hline $\mathbf{N 3}$ & 8.46 & 10.13 & 5.00 & $38.76^{*}$ & 13.37 \\
\hline $\mathbf{N} 4$ & 0.75 & 5.44 & 1.00 & 6.05 & 29.69 \\
\hline $\mathbf{N 5}$ & 1.25 & 6.36 & 1.00 & 9.18 & 22.98 \\
\hline N6 & 1.75 & 6.86 & 1.00 & 12.80 & 19.31 \\
\hline N7 & 2.75 & 7.80 & 1.41 & 16.80 & 17.09 \\
\hline N8 & 6.00 & 10.28 & 2.52 & 25.00 & 14.76 \\
\hline
\end{tabular}

* Extreme condition with turbine shut down

The FOWT was tested in two conditions outlined in Table 7. The configurations were selected in order to investigate independently the effect of the wind direction and wind field characteristics on the response of the system.

Table 7 Comparison configurations

\begin{tabular}{|c|c|c|c|c|}
\hline \multirow{2}{*}{ Configuration } & \multirow{2}{*}{ Wave direction } & \multirow{2}{*}{ Wind direction } & \multicolumn{2}{|c|}{ Wind model } \\
& & & T:turbulent(SIL) & C:constant \\
\cline { 3 - 5 } & & $0^{\circ}$ & Experiment & Numerical \\
\hline $\mathbf{1}$ & $0^{\circ}$ & $225^{\circ}$ & $\mathrm{T}$ & $\mathrm{T} / \mathrm{C}$ \\
\hline $\mathbf{2}$ & $0^{\circ}$ & & $\mathrm{T} / \mathrm{C}$ \\
\hline
\end{tabular}

All sea states and wind conditions were generated for a period of just less than three hours at full scale (30 minutes at model scale). The numerical study was designed to closely model the experiment conditions. The numerical study was performed at full scale and the experiment (model scale) results were scaled appropriately.

Figure 13 shows the model in the tank at wave heading and wind direction of $0^{\circ} / 0^{\circ}$ during one of the extreme tests. 


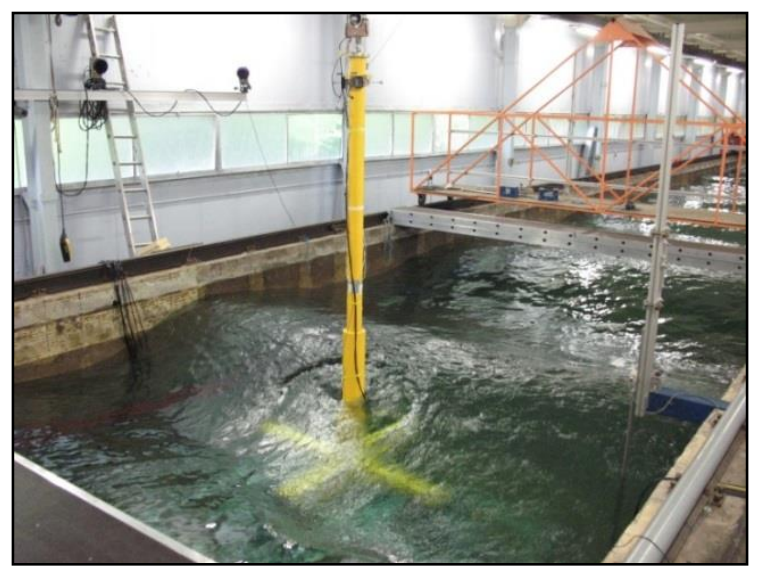

Figure 13 Extreme irregular wave test

\subsection{Results for storm condition}

This section describes detailed results for the extreme case for the $0^{\circ} / 0^{\circ}$ (wave/wind) condition. Motion and tendon tension probability density functions (pdf's) for the experimental and numerical predictions are given in the Figure 14- Figure 18.

It can be seen from Figure 14 and Figure 16 that the surge and heave motion pdf's for the experiments and the numerical predictions give, in general, good correlation. For pitch the numerical results are slightly higher than those of the experiment study near the peak response while the numerical results show less trim (mean pitch) than in the experiments. The location of the peaks of the motion pdf's (which represent the mean value of the responses) show that the TLP drifts downwind/wave by $0.65 \mathrm{~m}$, trims to the rear of the platform by 0.04 degrees and sinks by $0.03 \mathrm{~m}$ in the simulated storm case. In comparison to surge, pitch and heave motions, roll, sway and yaw motions were insignificant for all of the tests.

It can be seen that the agreement between numerical prediction and experimental data for surge motion in irregular waves shown in Figure 14 appears to be much better than in regular waves (Figure 9). There are two factors which contribute to this. Firstly, the greatest discrepancy in the regular wave tests occur in the region of the natural period, at around 25s; the agreement at periods less than $15 \mathrm{~s}$ is much better. The peak spectral period for the wave spectrum leading to the results shown in Figure 14 is around 10s, and the agreement of the surge RAO is much better at this period than at the peak of the RAO. A secondary effect may also be related to the viscous damping; in the regular wave tests, the surge may build up over several cycles to a large amplitude motion, especially for periods close to resonance, leading to a greater influence of non-linear viscous effects. In the irregular wave tests, any larger 
amplitude motions do not generally persist, and hence the neglect of viscous damping may be less important.

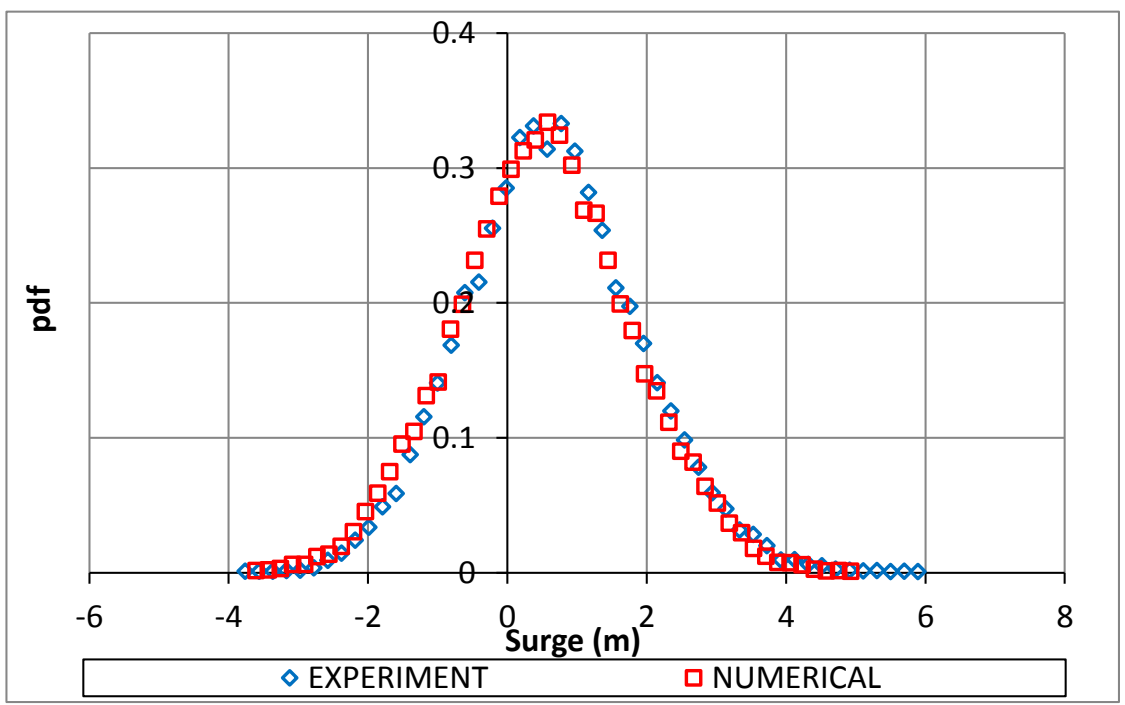

Figure 14 Correlation of surge motion pdf

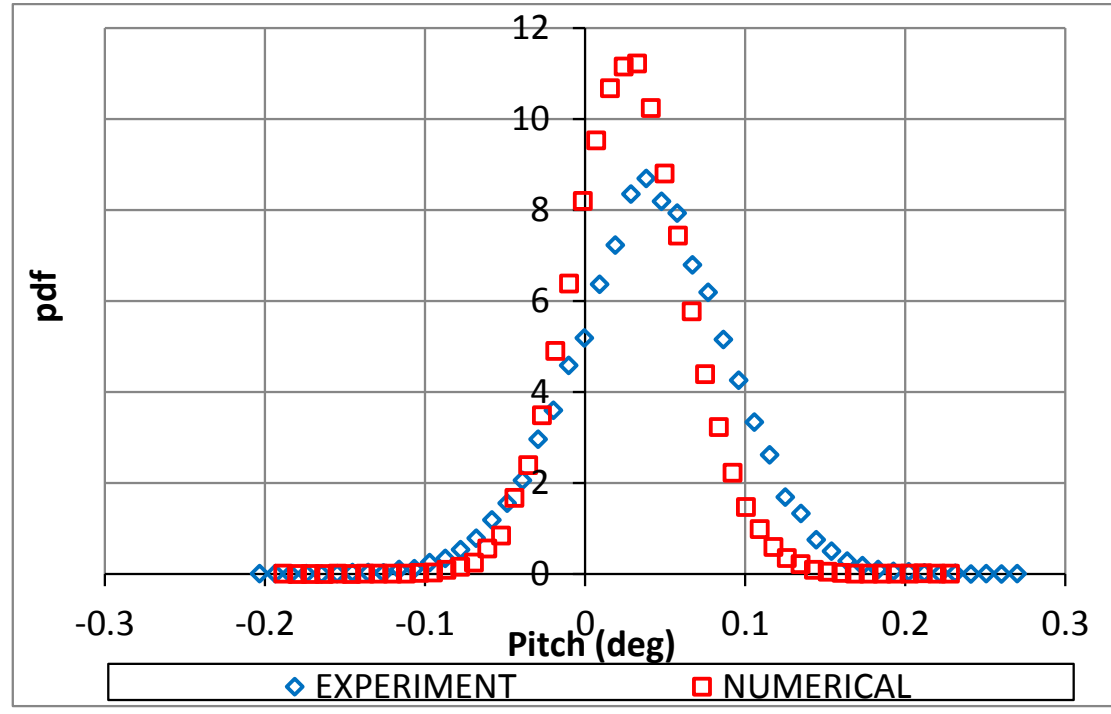

Figure 15 Correlation of pitch motion pdf 


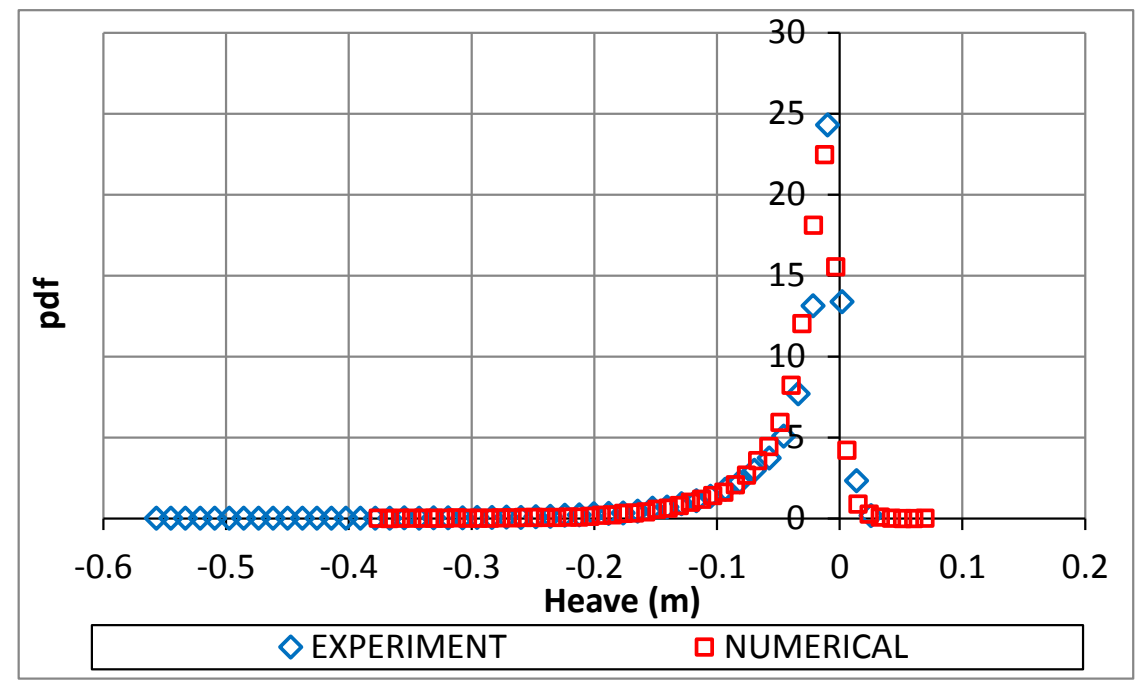

Figure 16 Correlation of heave motion pdf

Non-dimensional pdf's of front tendon tensions (mean of T1 and T2) are given in Figure 17, rear tensions (T5 and T6) are shown in Figure 18. It should be noted that FAST does not differentiate between individual tendon pairs. The nature of the pdf's is very similar although the numerical prediction substantially overestimates the mean value of tension shown by the shift of the location of the peak of the pdf. The experiment results show that the front tendons experience increased mean tension values while the rear tendons experience reduced tension compared to the initial tension values. It can be seen from Figure 17 and Figure 18 that the numerical method over-predicts both front and back tendon tensions, even though the prediction of the surge motion is accurate (Figure 14). It is speculated that this discrepancy in tendon tension may be related to the accuracy of the prediction of the pitch motion in the numerical approach as shown in Figure 15.

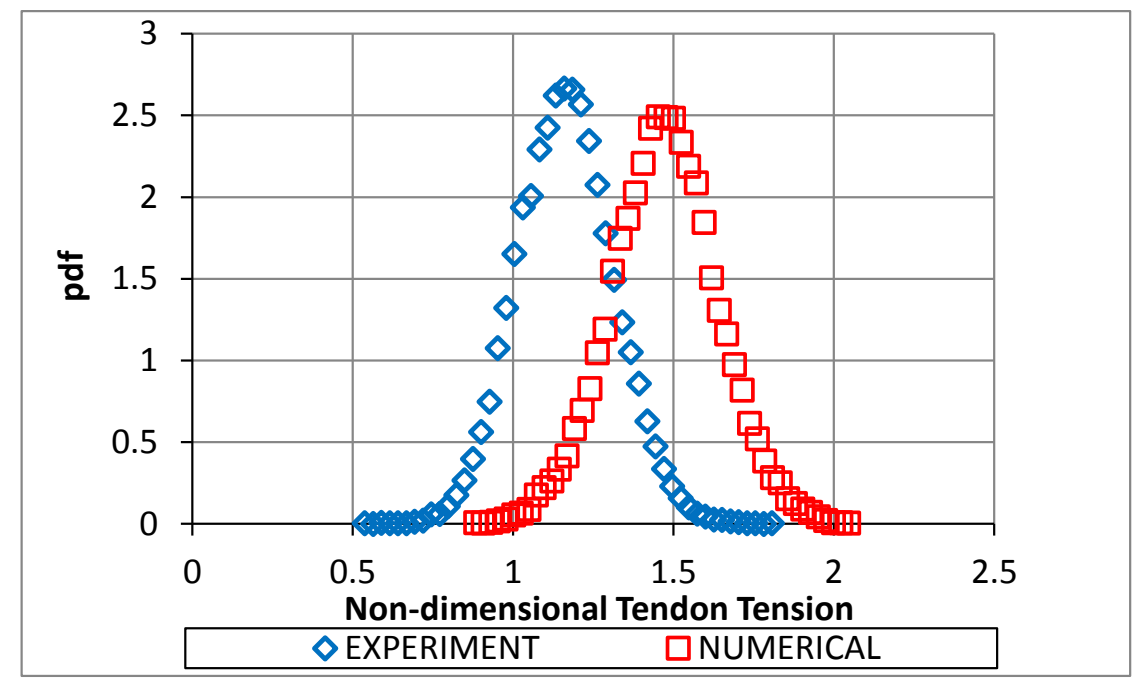

Figure 17 Front tendon tension pdf 


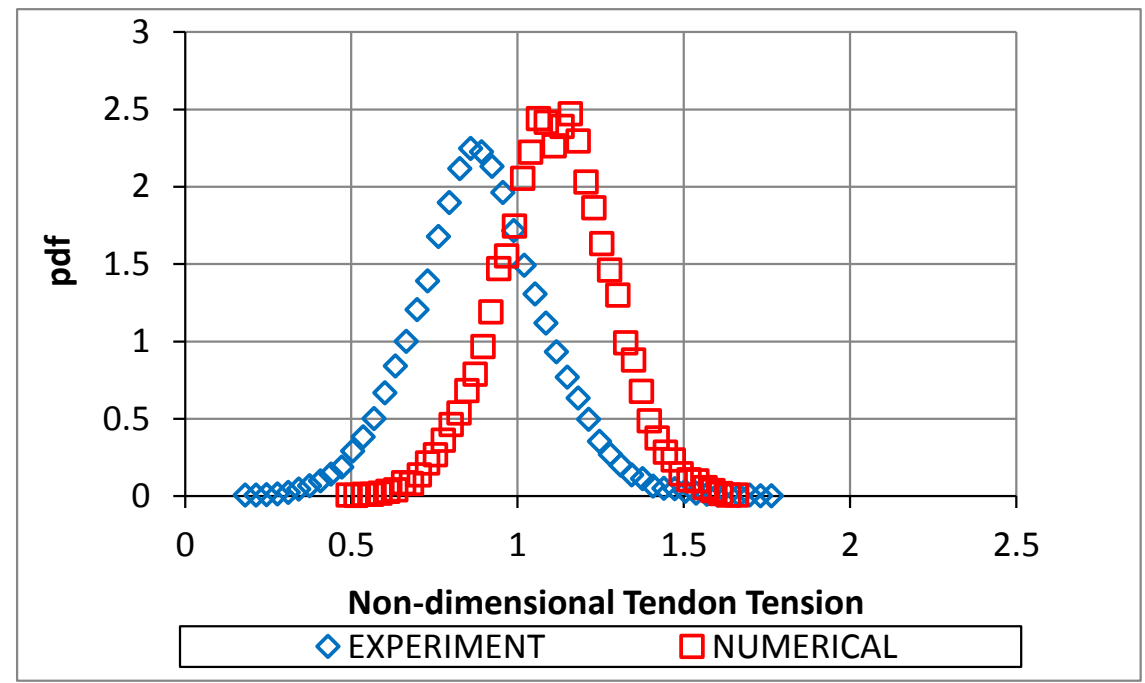

Figure 18 Back tendon tension pdf

Figure 17 and Figure 18 show that during the storm condition none of the tendons go slack i.e. tendon tensions are always greater than zero.

\subsection{Wave Direction $0^{\circ}$ Wind Direction $0^{\circ}$}

The irregular wave tests were performed for $0^{\circ} / 0^{\circ}$ wave/wind heading using five different sea states described in Table 8.

Table 8 Tests in $0^{\circ} / 0^{\circ}$ heading configuration

\begin{tabular}{|c|c|c|c|}
\hline Sea State & $\mathbf{H}_{\mathbf{s}}[\mathbf{m}]$ & $\mathbf{T}_{\mathbf{p}}[\mathbf{s}]$ & Wind Speed $[\mathbf{m} / \mathbf{s}]$ \\
\hline $\mathbf{N 5}$ & 1.25 & 6.36 & 9.18 \\
\hline $\mathbf{N 2}$ & 1.50 & 6.61 & 11.40 \\
\hline $\mathbf{N 6}$ & 1.75 & 6.86 & 12.80 \\
\hline $\mathbf{N 7}$ & 2.75 & 7.80 & 16.80 \\
\hline $\mathbf{N 3}$ & 8.46 & 10.13 & 38.76 \\
\hline
\end{tabular}

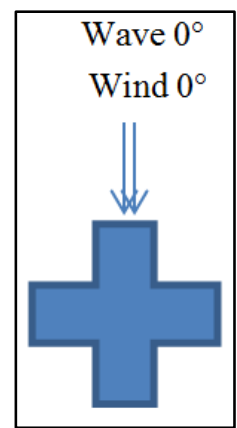

Figure 19 Configuration 1

\subsubsection{Drift and trim response}

The mean surge motion (drift) and mean pitch motion (trim) responses are presented in Figure 20 and Figure 21. For both cases the mean values from the experiments and from the 
numerical predictions show very similar trends. Hydrodynamic drift forces are neglected in FAST, so the mean drift is only due to wind which indicates that the hydrodynamic drift force is small in comparison. For wind speeds up to the rated turbine speed of $11.4 \mathrm{~m} / \mathrm{s}$ the Turbine is in 'Torque control' mode whereby the turbine torque and thrust increase with wind speed. Drift and trim displacements follows this trend. The maximum drift and trim are obtained for wind speeds near the rated turbine speed of $11.4 \mathrm{~m} / \mathrm{s}$ when the turbine thrust and power is at its maximum value. Above the turbine rated speed the turbine enters blade pitch control mode whereby the power is kept constant up to the cut out speed of $25 \mathrm{~m} / \mathrm{s}$. During this mode the turbine blades pitch progressively with increasing wind speed which reduces the turbine torque and thrust. A trend which can also be observed in both the drift and trim results. At wind speeds of $25 \mathrm{~m} / \mathrm{s}$ the thrust is around $30 \%$ of the value at rated speed due to the action of the blade pitch control. For the extreme condition (wind speed $>25 \mathrm{~m} / \mathrm{s}$ ) the rotor is shut down and the turbine thrust is zero. There is however significant drag force acting on the structure which accounts for the mean drift of around $0.6 \mathrm{~m}$ and mean pitch of 0.12 degrees.

It is interesting to note that numerical results employing the two wind models give very similar results: i.e. the turbulent effect of the wind does not affect the drift to a large extent. The numerical models and the experiments predict a maximum drift of around $1.4 \mathrm{~m}$.

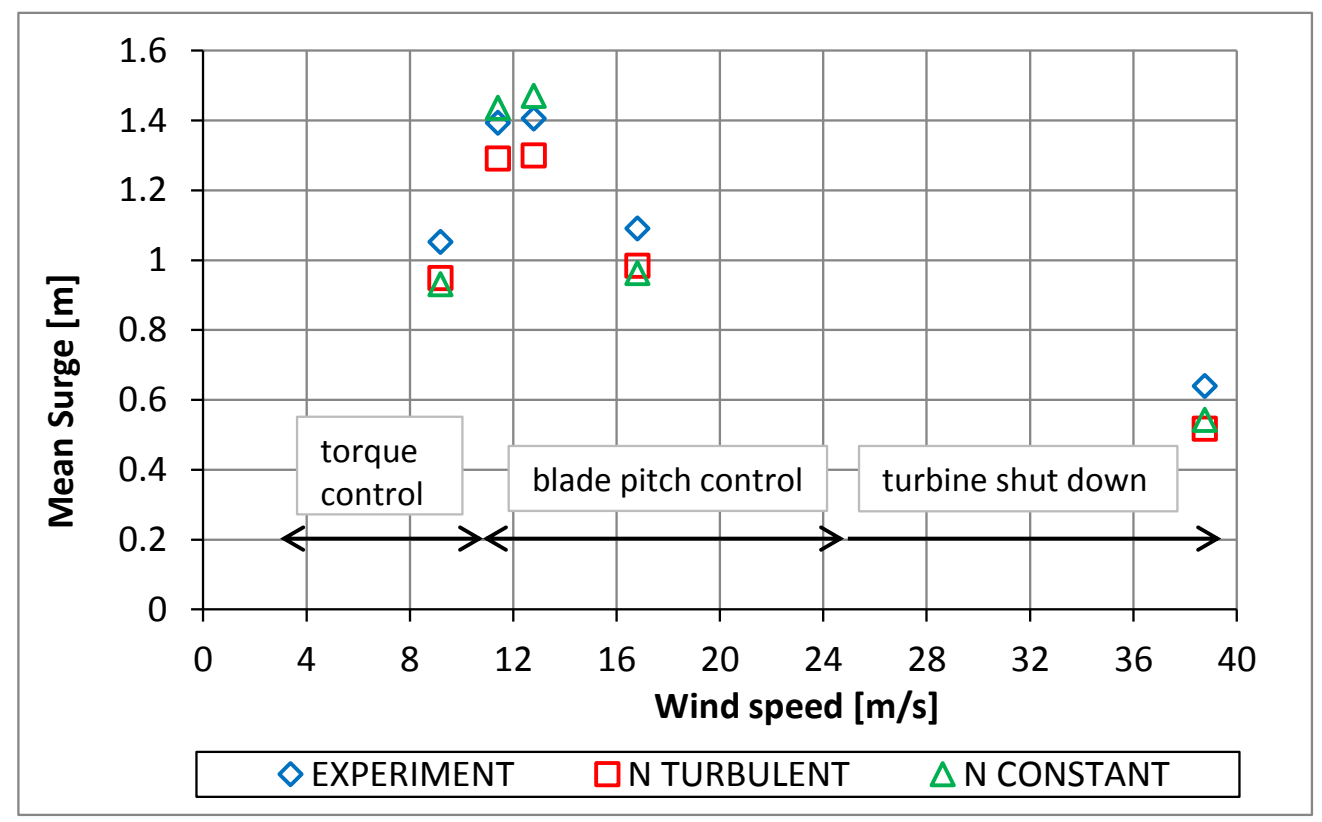

Figure 20 Mean value of surge motion wave 0 wind 0 


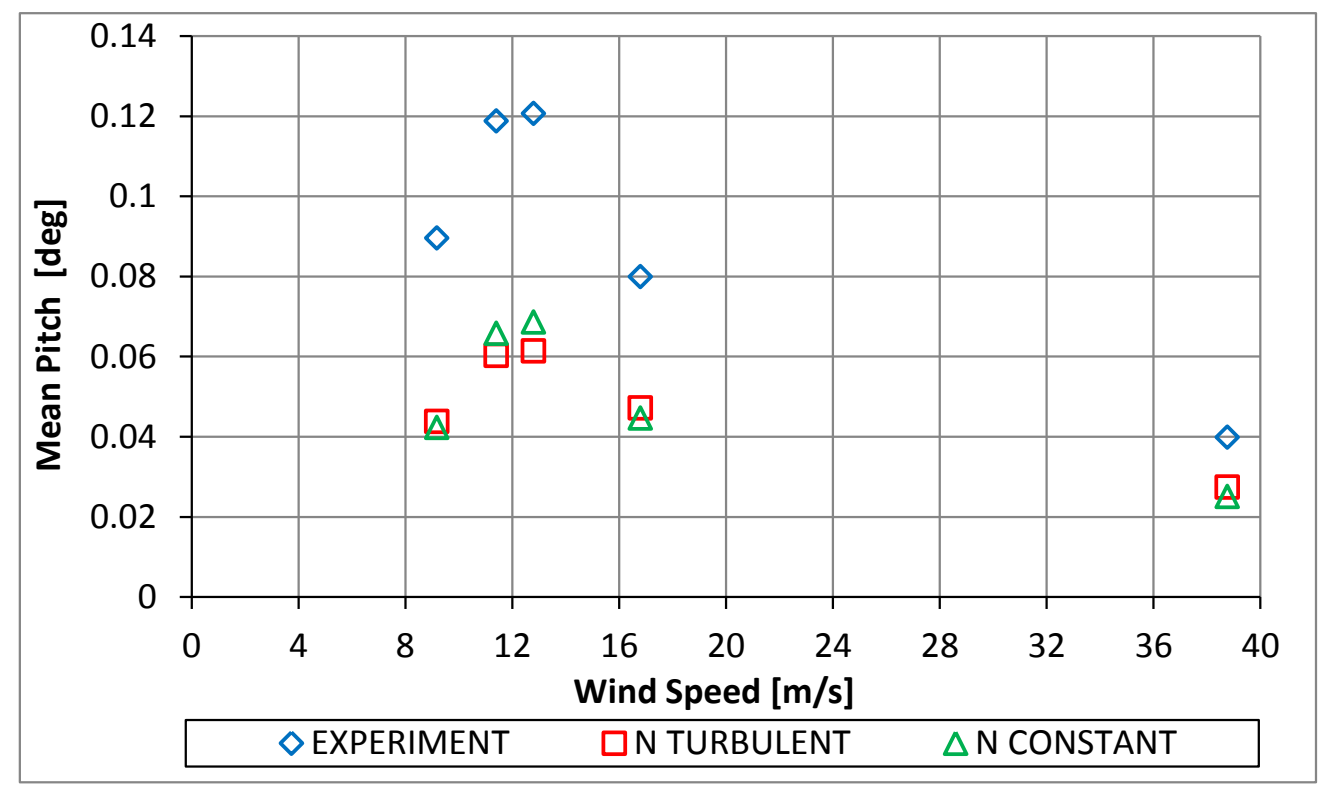

Figure 21 Mean value of pitch motion wave 0 wind 0

\subsubsection{Tendon tensions}

In this section, comparisons of non-dimensional total tendon tensions are presented. Total tensions are normalised as the ratio of total tension to static tension.

non - dimensional tension $=\frac{\text { total tension }}{\text { static tension }}$

Once again the average value of each tendon pair (which gave very similar results in the experiments) are presented. On the mean tension plots a tension value of 1 is equivalent to the static tendon pre-tension.

Figure 22 presents the mean tensions for the front and back tendons. The figure shows that the numerical results for the mean tensions are slightly higher than those obtained from the experiments. Front tendon tensions are always higher than back tendon tensions as expected, furthermore front tendon tensions are greater than the mean static tension and back tensions are lower than the mean static tension due to the influence of trim. The experiment results predict an increase in forward tensions of around $40 \%$ of the static value while the numerical prediction show a $60 \%$ increase. It is interesting to note that the two wind models give almost identical results. The maximum value of the mean tensions occurs at wind speeds in the region of the rated turbine speed $(11.4 \mathrm{~m} / \mathrm{s})$. Mean tendon tensions follow similar trends to the drift and trim results. The influence of the controller on the blade thrust at different wind speeds once again dominating the response of the system. 


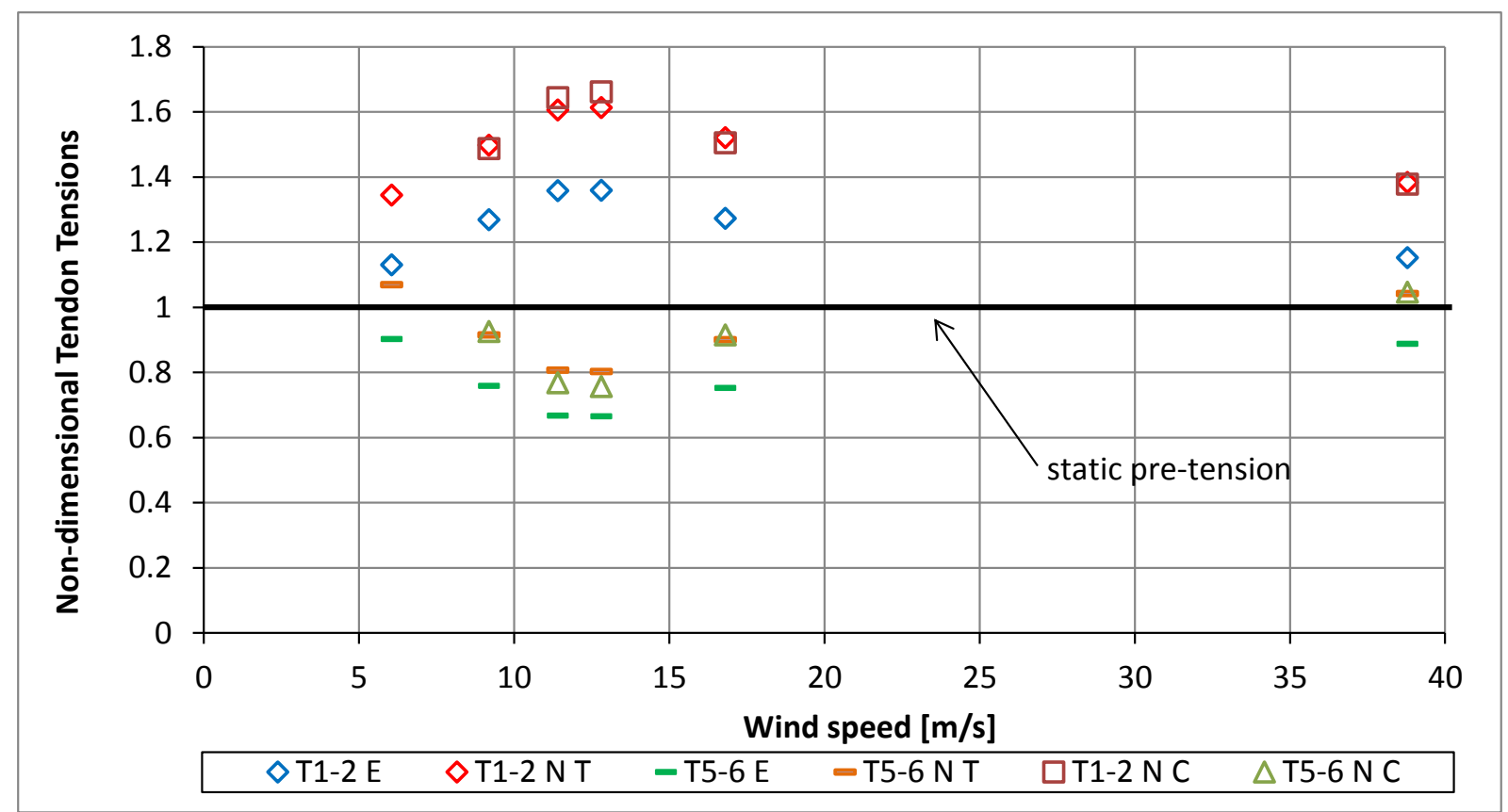

Figure 22 Mean tension values for front and back tendons

Figure 23 presents the mean tensions for the side (T3 and T4) / (T7 and T8) tendons. Once again the numerical results for the mean tensions are higher than those obtained from the experiments. The experimental results show that the mean tensions are 1-2\% higher that the static tension values with the numerical predictions $20 \%$ higher than the static values of tension. Both the experiment and numerical results show that the mean side tensions are almost independent of wind speed. The two wind models once again give almost identical results. 


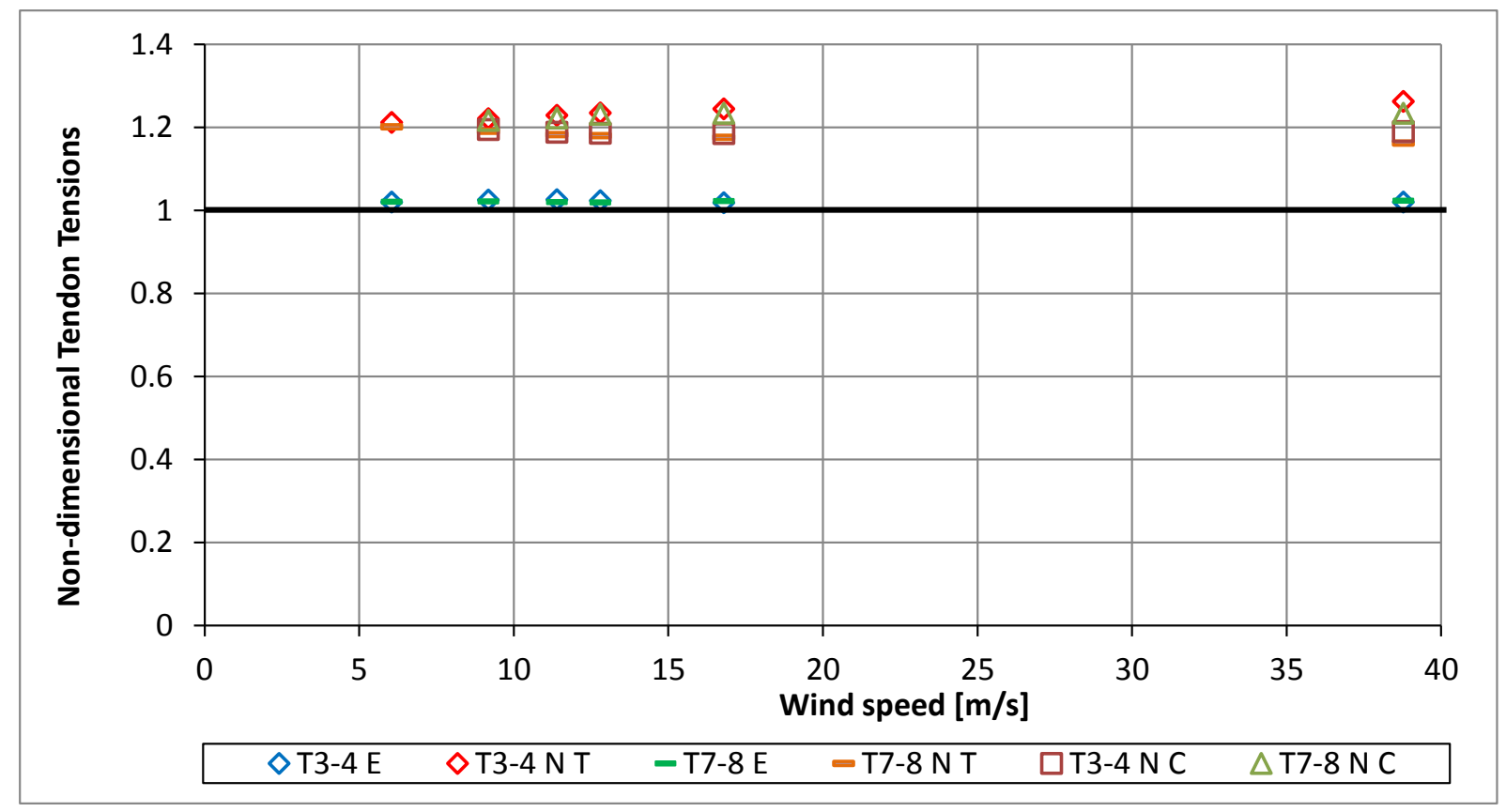

Figure 23 Mean tension values for side tendons

Due to the geometry of the platform the influence of trim on the side tendon tensions is small while the influence of trim on the front/rear tensions is large. Since all of the platform tendons experience similar effects due to drift it seems that trim has the greatest effect on the mean tendon tensions for the front and rear tendons while side tensions are slightly influenced by the platform drift.

\subsection{Wave Direction $0^{\circ}$ Wind Direction $225^{\circ}$}

Irregular wave tests were performed for $0^{\circ} / 225^{\circ}$ wave/wind heading using seven different sea states described in Table 9.

Table 9 Tests in $0 / 225$ heading configuration

\begin{tabular}{|c|c|c|c|}
\hline Sea State & $\mathbf{H}_{\mathbf{s}}[\mathbf{m}]$ & $\mathbf{T}_{\mathbf{p}}[\mathbf{s}]$ & Wind Speed $[\mathbf{m} / \mathbf{s}]$ \\
\hline $\mathbf{N 4}$ & 0.75 & 5.44 & 6.05 \\
\hline $\mathbf{N 5}$ & 1.25 & 6.36 & 9.18 \\
\hline $\mathbf{N 2}$ & 1.50 & 6.61 & 11.40 \\
\hline $\mathbf{N 6}$ & 1.75 & 6.86 & 12.80 \\
\hline $\mathbf{N 1}$ & 4.55 & 9.00 & 11.40 \\
\hline $\mathbf{N 8}$ & 6.00 & 10.28 & 25.00 \\
\hline $\mathbf{N 3}$ & 8.46 & 10.13 & 38.76 \\
\hline
\end{tabular}




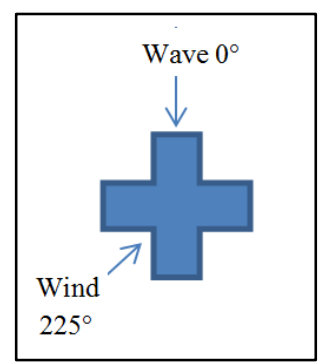

Figure 24 Configuration 2

Variation in wind direction was achieved by rotating the fan on top of the tower.

\subsubsection{Drift and Trim response.}

Drift and trim responses for the case of $0^{\circ}$ head waves and $225^{\circ}$ wind direction are presented in Figure 25 and Figure 26. The mean values from the experiments and from the constant wind numerical model show very similar trends while the turbulent model results show more scatter. All of the values for trim and drift are negative indicating that the aerodynamic forces are greater than the hydrodynamic forces and the platform drifts towards the direction of the incident waves and trims towards the waves. The maximum trim and drift values once again occur at the turbine rated wind speed. Both trim and surge follow similar trends to the $0 \% 0^{\circ}$ case with the controller setting once again dominating the response of the platform. The experiments predict a maximum drift of around $1 \mathrm{~m}$ compared to $1.4 \mathrm{~m}$ for the $0 \% 0^{\circ}$ case. Maximum trim is 0.12 which is the same as the $0^{\circ} / 0^{\circ}$ case albeit in the opposite direction. This indicates that the waves influence the platform drift but have only a small effect on the platform trim which seems to be dominated by the aerodynamic forces.

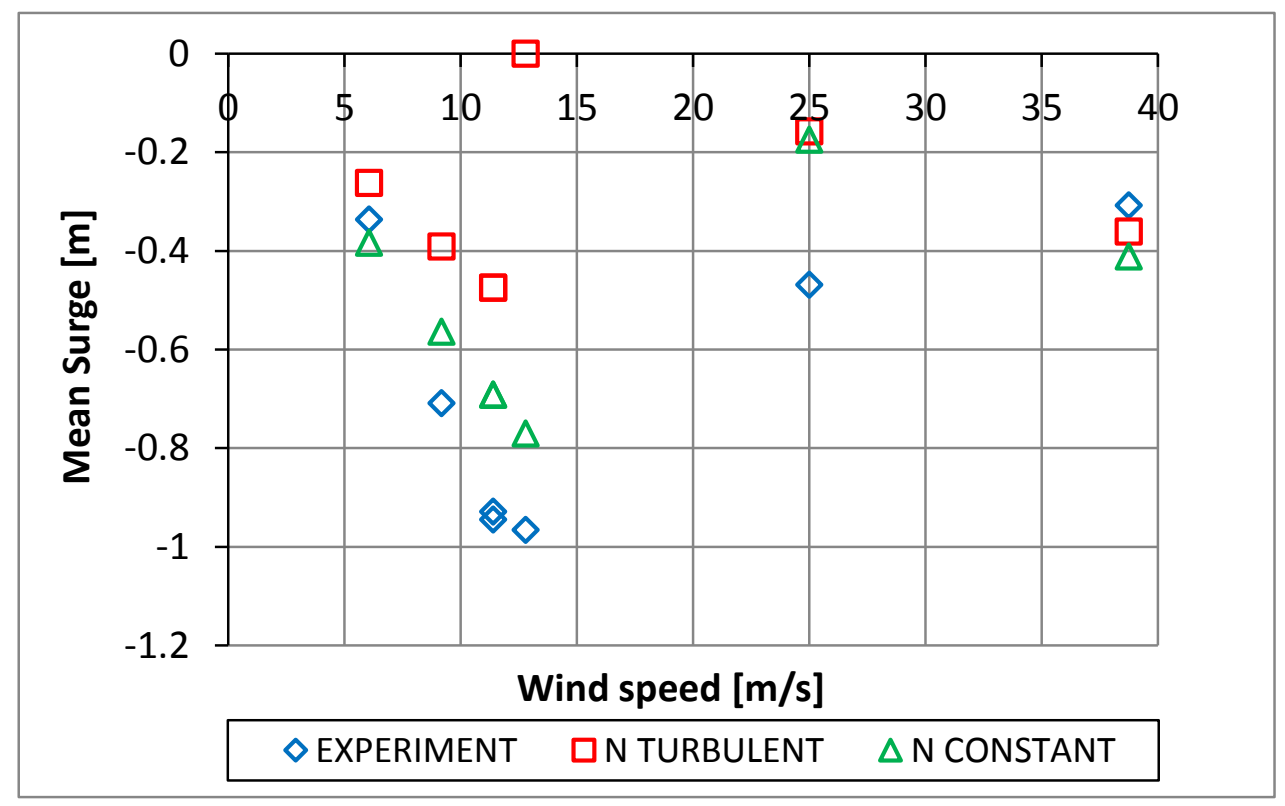

Figure 25 Mean value of surge motion wave 0 wind 225 


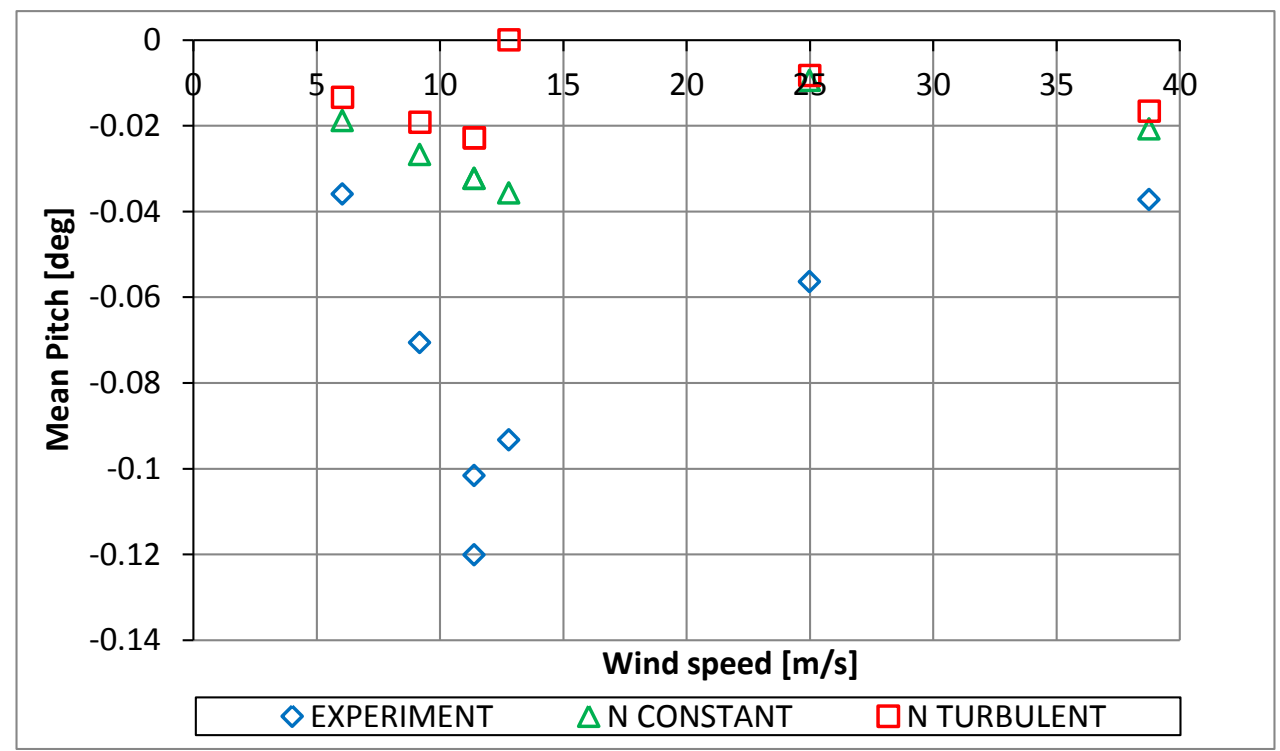

Figure 26 Mean value of pitch motion wave 0 wind 225

\subsubsection{Tendon Tensions}

Figure 27 presents the mean tensions for the front and back tendons. The numerical results for the mean tensions are slightly higher than those obtained from the experiments. In contrast to the $0^{\circ} / 0^{\circ}$ case front tendon tensions are lower than back tendon tensions due to the dominance of the aerodynamic forces over the hydrodynamic forces. The maximum mean tendon tensions are very slightly lower than those obtained in the $0^{\circ} / 0^{\circ}$ case due to the hydrodynamic forces now opposing the aerodynamic forces in this test condition. The trends for the mean tension values are similar and the two wind models once again give almost identical results. Once again the largest mean tensions occur in the region of rated turbine wind speed. 


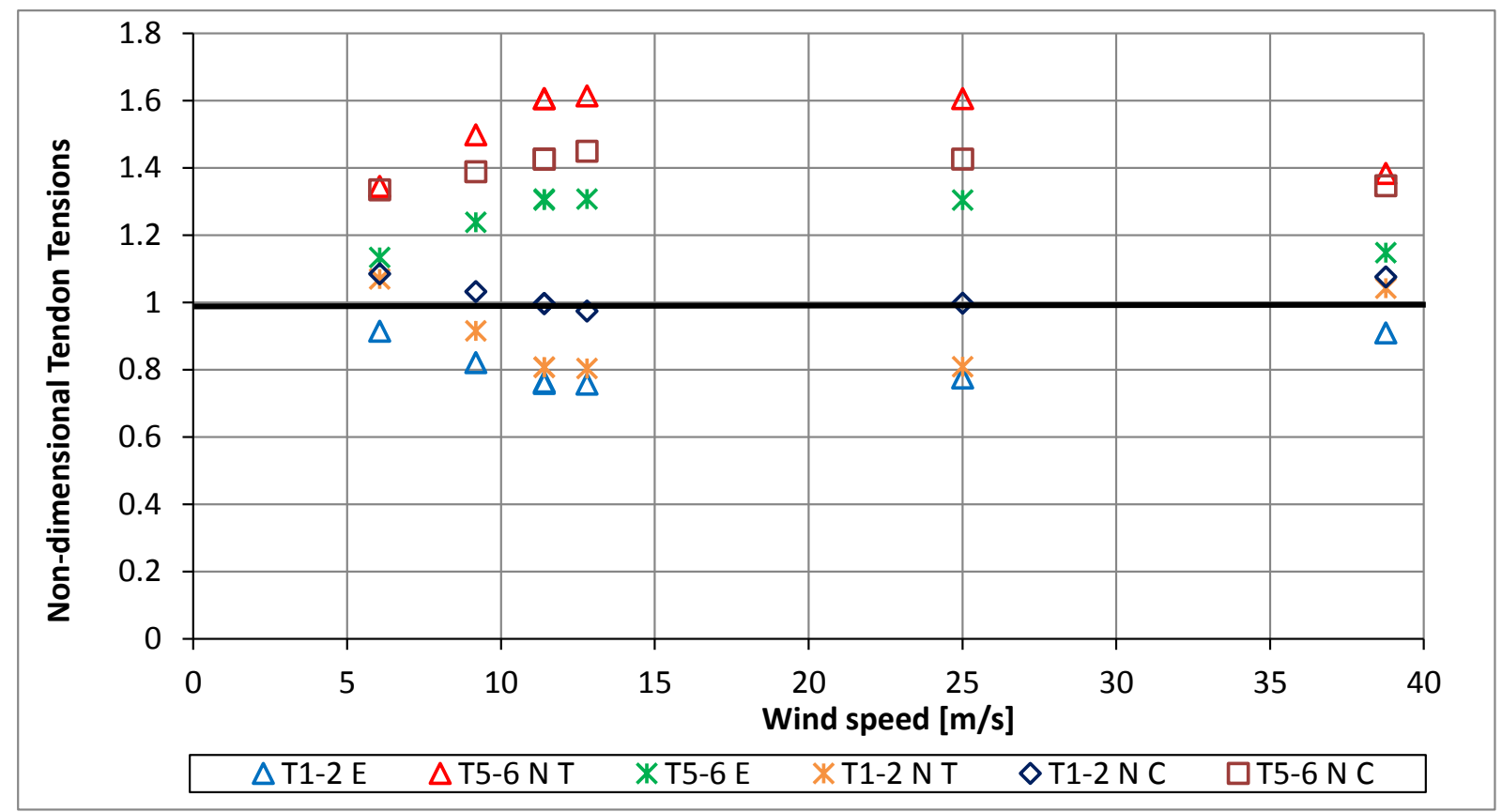

Figure 27 Mean tension values for front and back tendons

Figure 28 presents the mean tensions for the side tendons. The mean tension for tendons 3 and 4 fall below the static pretension value while the opposite tendon pair 7 and 8 have mean tendons above the static pretension value. The experiments results show that the side tendons have maximum values at the turbine rated speed and also follow the trends seen previously on the front/back tendons albeit by a smaller amount. This is due to a small steady heel being introduced due to the direction of the aerodynamics forces. The numerical predictions fail to show this subtle effect. 


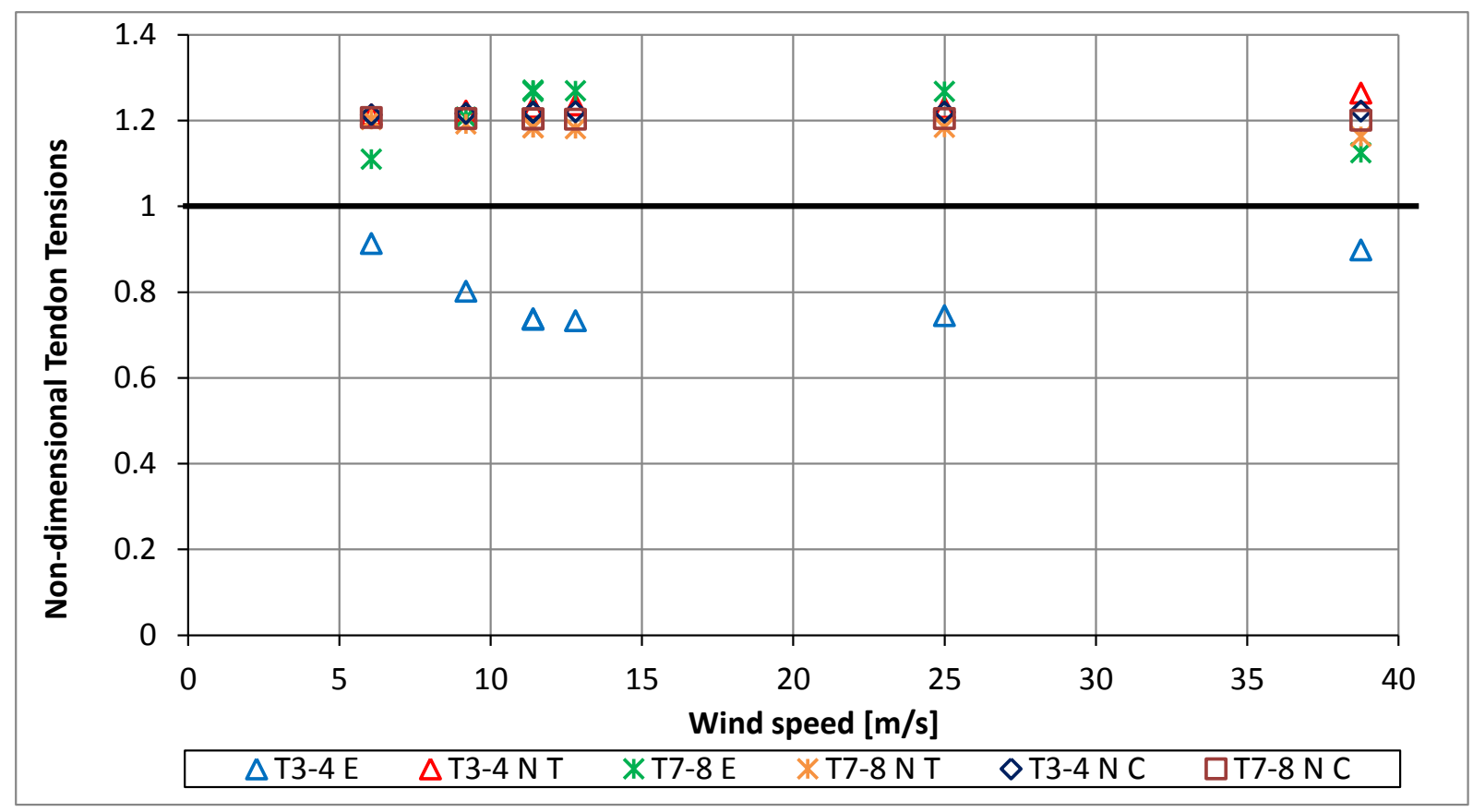

Figure 28 Mean tension values for side tendons

\section{Conclusions}

This paper describes the characterisation of a FOWT in simulated realistic operating conditions using both experimental and numerical approaches. The results from both approaches are presented and compared. The tests consisted of free oscillation tests in surge and pitch, regular wave tests and irregular wave tests in simulated wave and wind conditions.

The free oscillation results showed good correlation between the numerical and experiment approaches with surge natural periods agreeing to within $9 \%$ and pitch to within $1.5 \%$. Both natural periods (surge 24 seconds, pitch 2.5 seconds) are outwith the regions where the influence of waves is significant. All of the motion and tendon tensions responses showed good agreement for wave periods between 5 to 15 seconds and from around 28 seconds but the numerical results significantly overestimate the motion responses near the 24 seconds surge natural period. Dynamic tendon tensions for the down-wave pair were only slightly larger than the up-wave pair with the side tendons showing the smallest variation. Maximum tendon tensions coincided with the maximum surge motion at a period of around 24 seconds. The numerical results once again over predicted the tendon tensions in the region of the surge natural period.

Results from the extreme case showed that the surge, pitch and heave motion pdf's for the experiments and the numerical predictions give, in general, good correlation. The mean 
position of the platform drifts downwind / wave by $0.65 \mathrm{~m}$, trims to the rear of the platform by 0.04 degrees and sinks by $0.03 \mathrm{~m}$ in the simulated storm case. In comparison to surge, pitch and heave motions, roll, sway and yaw motions were insignificant for all of the tests. The nature of the tendon tension pdf's was very similar although the numerical prediction substantially overestimates the mean value of tendon tension.

The irregular wave study focussed on the mean platform drift, trim and tendon tensions. In general the results are closely related to effect of the turbine thrust on drift and trim which results in variations in mean tendon tension - the trim effect being dominant. The experiment results showed that the wave induced second order forces were small in comparison to the aerodynamic forces. Second order hydrodynamic effects are not included in the numerical model. Drift and trim responses from the experiments and from the numerical predictions show very similar trends. The maximum drift and trim are obtained for wind speeds near the rated turbine speed of $11.4 \mathrm{~m} / \mathrm{s}$ when the turbine thrust is at its maximum value. Above rated wind speed the turbine blades pitch progressively with increasing wind speed which reduces the turbine thrust. The trim and drift values were shown to be closely correlated with the turbine thrust. This illustrates the importance of the turbine control system in maintaining the mean responses within acceptable limits.

Further investigation is required to explain why, in some cases, the numerical predictions were very close to the results obtained from the experiments but in other cases the numerical model failed to accurately predict the platform response. Also the variable effect of wind model (constant vs turbulent) on the numerical results requires further study. The experimental study proved to be a very costly and time consuming process compared to the relative ease of obtaining the numerical predictions. However, the results in the present study suggest that, until the numerical discrepancies are resolved, carefully conducted experiments which properly take into account turbine thrust are essential in order to characterise the performance of FOWTs. 


\section{ACKNOWLEDGEMENTS}

First author gratefully acknowledges the funding sources that made her $\mathrm{PhD}$ work possible. She was funded by Lloyd's Register and University of Strathclyde for the first two years of her PhD. She was also partially supported by Department of Naval Architecture, Ocean and Marine Engineering by a research assistant position. The work was funded under the Innovate UK grant "TLPWind UK: Driving down the cost of offshore wind in UK waters", project reference 101969. Special thanks are also given to José Azcona Armendáriz and Faisal Bouchotrouch from CENER (National Renewable Energy Centre of Spain) for their support. 


\section{REFERENCES}

Bachynski, E. E., \& Moan, T., 2012. Design considerations for tension leg platform wind turbines. Marine Structures, 29(1), 89-114.

Bulder, B. H., Henderson, A., Huijsmans, R. H. M., Peeringa, J. M., Pierik, J. T. G., Snijders, E. J. B., Hees, M.T., Wijnants, G.H., Wolf, M. J., 2003. Floating offshore wind turbines for shallow waters. In European Wind Energy Conference (EWEC).

Goupee, A. J., Koo, B., Kimball, R. W., Lambrakos, K. F., Dagher, H. J., 2012. Experimental Comparison of Three Floating Wind Turbine Concepts. OMAE 2012. Rio de Janeiro, Brazil.

Henderson, A. R., Morgan, C. S., Smith, B., Sorensen, H. C., Barthelmie, R. J., Boesmans, B., 2003. Offshore Wind Enegy in Europe, A Review of the State-of-the-Art. Wind Energy, 6, 35-52.

IEC 61400-3, 2009. International Electrotechnical Commission Standard on Wind Turbines, Part3: Design Requirements for ffshore wind turbines.

Jonkman, J. M., 2007. Dynamics Modeling and Loads Analysis of an Offshore Floating Wind Turbine. PhD Thesis, University of Colorado, Boulder, CO, USA.

Jonkman, J. M., Butterfield, S., Musial, W., Scott, G., 2009. Definition of a 5-MW Reference Wind Turbine for Offshore System Development. Technical Report, National Renewable Energy Laboratory (NREL), Golden, CO, USA.

Jonkman, J., 2010. Definition of the Floating System for Phase IV of OC3. Technical Report, National Renewable Energy Laboratory (NREL), Golden, CO.

Jonkman, J., Musial, W., 2010. Offshore Code Comparison Collaboration (OC3) for IEA Task 23 Offshore Wind Technology and Deployment. NREL.

Lee, K.H., 2005. Responses of floating wind turbines to wind and wave excitation. MSc Thesis. University of Michigan.

Manjock, A., 2005. Desing codes FAST and ADAMS for load calculations of onshore wind turbines, Report No. 72042, Germanischer Lloyd WindEnergie GmbH, Hamburg, Germany.

Martin, H. R., Kimball, R. W., Viselli, A. M., Goupee, A. J., 2012. Methodology for wind/wave basin testing of floating offshore wind turbines. OMAE 2012. Rio de Janeiro, Brazil.

Matha, D., 2009.Model Development and Loads Analysis of an Offshore Wind Turbine on a Tension Leg Platform, with Comparison to Other Floating Turbine Concepts. Thesis M.E., University of Colorado, Boulder.

Müller, K., Sandner, F., Bredmose, H., Azcona, J., Manjock, A., Pereire, R., 2014. Improved Tank Test Procedures for Scaled Floating Offshore Wind Turbines. International Wind Engineering Conference, IWEC.

Nielsen, F.G., Hanson, T.D., Skaare, B., 2006. Integrated dynamic analysis of floating offshore wind turbines. In : Proceedings of the international conference on Ocean, Offshore and Arctic Engineering (OMAE), Harmbugh, Germany, 4-9 June, 2006.

Nihei, Y., Fujioka, H., 2010. Motion characteristics of a TLP type offshore wind turbine in waves and wind. Proceedings of $29^{\text {th }}$ International Conference on Ocean, Offshore and Arctic Engineering, (OMAE) - 21126.

Nihei Y, Iijima K, Murai M, Ikoma T., 2014. A Comparative Study of Motion Performance of Four Different FOWT Designs in Combined Wind and Wave Loads. ASME. International Conference on Offshore Mechanics and Arctic Engineering, Volume 7: Ocean Space Utilization; Professor Emeritus J. Randolph Paulling Honoring Symposium on Ocean Technology ():V007T05A025. doi:10.1115/OMAE2014-24643. 
Oguz, E., Day, A.H., Clelland, D., Incecik, A., Dai, S., Lopez, J.A., González, G., Sánchez, G., 2016. Experimental Study of a TLP Offshore Floating Wind Turbine. Proceedings of International Conference on Maritime Technology, Harbin, China.

Roddier, D., Cermelli, C., Aubault, A., Weinstein, A., 2010. WindFloat: A floating foundation for offshore wind turbines. Journal of Renewable and Sustainable Energy, 2.

Rodriguez, R. Z., Alonso, P. G., Lopez, J. A., Martin, V. D., Dinoi, P., Simos, A. N., Iglesias, A. S., 2014. Model Scale Analysis of a TLP Floating Offshore Wind Turbine. OMAE2014. San Francisco, California, USA.

Shin H., Kim B., Dam P.T., Jung K., 2013. Motion of OC4 5 MW Semi-submersible Offshore Wind Turbine in irregular waves. In: Proceedings, 32nd International Conference on Ocean Offshore \& Arctic Eng., OMAE2013-10463 Nantes, France.

Skaare, B., Hanson, T.D., Nielsen, F.G., Yttervik, R., Hansen, A.M., Thomsen, K., Larsen, T.J., 2007. Integrated Dynamic Analysis of Floating Offshore Wind Tubines. European Wind Energy Association (EWEA).

Sclavounos, P., Tracy, C., Lee, S., 2007. Floating Offshore Wind Turbines: Responses in a Seastate Pareto Optimal Designs and Economic Assessment. Department of Mechanical Engineering, Massachusetts Institute of Technology.

Tracy, C., 2007. Parametric Design of Floating Wind Turbines. Master of Science, Massachusetts Institute of Technology (MIT).

Vijfhuizen, W. J.M.J., 2006. Design of Wind and Wave Power Barge. MSc Thesis, Department of Naval Architecture and Marine Engineering.

Wayman, E., Sclavounos, P., Butterfield, S., Jonkman, J., Musial, W., 2006. Coupled dynamic modeling of floating wind turbine systems. Offshore Technology Conference Houston, Texas.

Withee, J.E, Sclavounos, P.D., 2004. Fully Coupled Dynamic Analysis of a Floating Wind Turbine System, Proceedings of $8^{\text {th }}$ World Renewable Energy Congress, Denver, USA.

Zhao, Y., Yang, J., He, Y., 2012.Preliminary Design of a Multi-Column TLP Foundation for a 5-MW Offshore Wind Turbine. Energies, 2012, 5(10), pp.3874-3891. 